\author{
Luis Carlos Martínez Fernández e Ignacio Molina de la Torre \\ Departamento de Geografía. Universidad de Valladolid
}

\title{
La configuración espacial reciente de la ciudad de Ávila
}

\section{Resumen}

Ávila se define como una ciudad media en el contexto de Castilla y León. Su configuración reciente responde a un intenso proceso de ampliación del espacio construido. Un impulso urbano que, sin embargo, no encuentra correlato en un cambio de las funciones tradicionales como centro de administración y servicios provincial. La atonía de las actividades económicas lastra, a la postre, la dinámica territorial.

\section{RÉSUMÉ}

La configuration spatiale récente de la ville d'Avila.- Ávila est une ville moyenne dans le contexte régional de Castilla y León. Sa configuration récente découle d'un intense processus d'élargissement de l'espace bâti. Il s'agit d'un élan urbain qui toutefois ne s'accompagne pas d'un changement de fonctions en tant que centre administratif et de services dans sa province. L'atonie des activités économiques empêche en fin de compte la dynamique territoriale.

\section{I. ÁVILA EN SU CONTEXTO GEOGRÁFICO}

\section{Ciudad media, CENTRO PROVINCIAL Y POSICIONAMIENTO ESTRATÉGICO}

$E^{s}$ un lugar común, en la literatura académica preocupada por estas cuestiones, el identificar a los núcleos urbanos de talla demográfica superior a los 50.000 habitantes e inferior a los 500.000 con el concepto de ciudad media (Andrés, 2008). Esta nomenclatura adquiere pleno sentido en la clasificación por rango y tamaño de las ciudades europeas y también, en buena medida, españolas. Para Castilla y León, sin embargo, y dada la debilidad que caracteriza a su sistema de poblamiento, se ha
ABstract

Recent spatial configuration of the city of Avila.- Avila is defined as an medium-sized city in the Castilla y León context. Its recent configuration responds to an intense process of enlargement of the built space. An urban impulse, however, is not correlated to a change in the traditional functions as a center of administration and provincial services. The weakness of economic activities hampers, after all, territorial dynamics.

\section{Palabras Clave/Mots clé/Keywords}

Transformación espacial, dinámica urbana, Ávila, ciudad media. Transformation de l'espace, dynamique urbaine, Ávila (Espagne), ville moyenne.

Spatial transformation, urban dynamics, Ávila (Spain), medium-size city.

convenido en rebajar ese umbral inicial al menos a los 30.000 residentes (López, 1998). Así es como los mayores enclaves poblacionales de la comunidad se singularizan como las doce ciudades principales de la misma, siendo considerados, además, los elementos básicos en la articulación y vertebración del vasto espacio autonómico (94.147 kilómetros cuadrados) (Manero, 1995 y 2003). En total 1.220 .863 castellanos y leoneses (el 47,7 \% del total) vivían en 2011 en alguna de las nueve capitales de provincia o en los centros industriales de Ponferrada, Miranda de Ebro o Aranda de Duero. En una suma, empero, que no encubre los manifiestos contrastes existentes en la cuantía y proporción de los vecindarios de cada uno de estos núcleos, todos ellos ciudades medias (desde el 


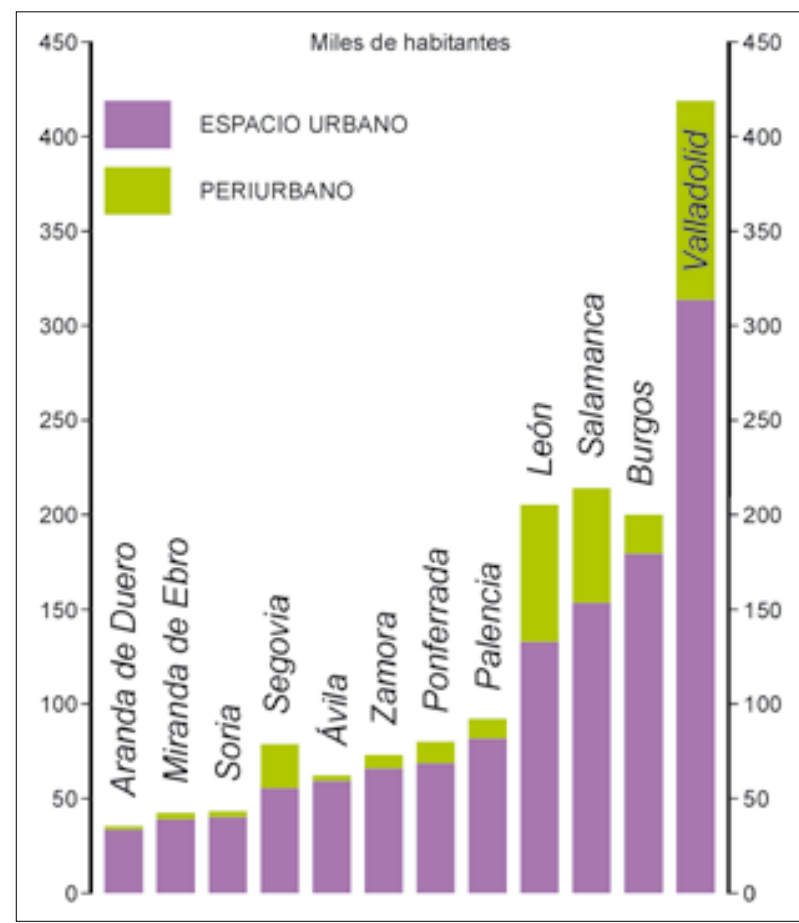

FIG. 1. Jerarquía de las áreas urbanas de Castilla y León en 2011. Fuente: elaboración propia a partir de INE: Padrón municipal de habitantes.

último de los citados a Valladolid), diferenciándose claramente tres niveles jerárquicos en lo que es la cúspide del armazón territorial de la región (Martínez y Delgado, 2013).

La trama urbana de Castilla y León, comparada con la del resto del país, puede ser calificada de frágil, endeble y laxa, lo que sin duda refuerza la imagen rural de la comunidad y subraya la presencia de amplios espacios vacíos y desarticulados. En cualquier caso, se ha ido conformando en la región una cierta jerarquía del sistema de asentamientos y una red en la que sobresale la progresiva expansión de la aglomeración vallisoletana, identificada como centro regional. Sus dimensiones como tal son las otorgadas por los 313.437 residentes en la capital en 2011 (4.856 menos que en 2001), a los que se unen los 105.252 habitantes (43.306 más que a comienzos del decenio) de otros trece municipios periurbanos y quince de influencia urbana (destacando el caso de Laguna de Duero, con 22.334 habitantes, superando a Medina del Campo como segundo núcleo en cuantía poblacional de la provincia).

A gran distancia de Valladolid, en un segundo nivel, a modo de centros subregionales, aparecen las ciudades de Burgos, Salamanca y León y sus correspondientes contornos de crecimiento. Es León, curiosamente, y a pesar
CuAdro I. Población residente en los municipios del área urbana de Ávila, 2001-2011

\begin{tabular}{|c|c|c|}
\hline \multirow[b]{2}{*}{ Municipio } & \multicolumn{2}{|c|}{ Población } \\
\hline & 2001 & 2011 \\
\hline Ávila & 47.967 & 59.008 \\
\hline La Colilla & 223 & 345 \\
\hline El Fresno & 493 & 568 \\
\hline Herradón de Pinares & 493 & 525 \\
\hline Martiherrero & 194 & 296 \\
\hline Navalperal de Pinares & 806 & 1.066 \\
\hline Tornadizos de Ávila & 362 & 424 \\
\hline TOTAL área urbana & 50.538 & 62.232 \\
\hline TOTAL provincial & 163.885 & 172.704 \\
\hline
\end{tabular}

Fuente: elaboración propia a partir de INE: Padrón municipal de habitantes.

de ser de las grandes capitales la de tamaño demográfico más modesto, la primera en configurar un área urbana en la comunidad. A sus 132.744 empadronados se suman los 72.450 (con una ganancia total de 22.448 entre 2001 y 2011) que lo hacen en alguno de los siete y tres municipios catalogados, respectivamente, como periurbanos y de influencia urbana (contando con el primero de estas características surgido en la región, al tiempo que el de vecindario más abultado, San Andrés del Rabanedo, con 31.562 habitantes). Salamanca, por su parte, añade con los 14.853 residentes del municipio periurbano de Santa Marta de Tormes, más otros 45.959 repartidos por veintiséis entidades del área de influencia, la cuantía padronal de la capital, cifrada en 153.472; con un crecimiento global de la aglomeración en los diez años reseñados de 22.949 personas. Burgos, por último, cuenta con un extenso término municipal, en el que se resuelven, en parte, las dinámicas inherentes a la difusión de los crecimientos periféricos. Así se explica que sea la única de las cuatro principales capitales que consiga seguir aumentando sus vecindarios (pasa de 166.251 habitantes, en 2001, a 179.251, en 2011); si bien treinta y seis municipios de su entorno ya pueden ser catalogados como áreas de influencia, en un proceso que va consolidándose (20.590 residentes, 8.444 más a lo largo de los últimos diez años).

Tras estas cuatro capitales, otras ocho ciudades y sus entornos se erigen en lo que, en un tercer nivel jerárquico del sistema de poblamiento regional, teniendo en cuenta la escala de sus influjos, se denominan «centros provinciales». Palencia es la primera de ellas. Cuenta con 81.552 habitantes (incluso 716 más que en 2001) y con un contorno de crecimiento que abarca a otros cuatro municipios, dos propiamente periurbanos y otros dos ti- 


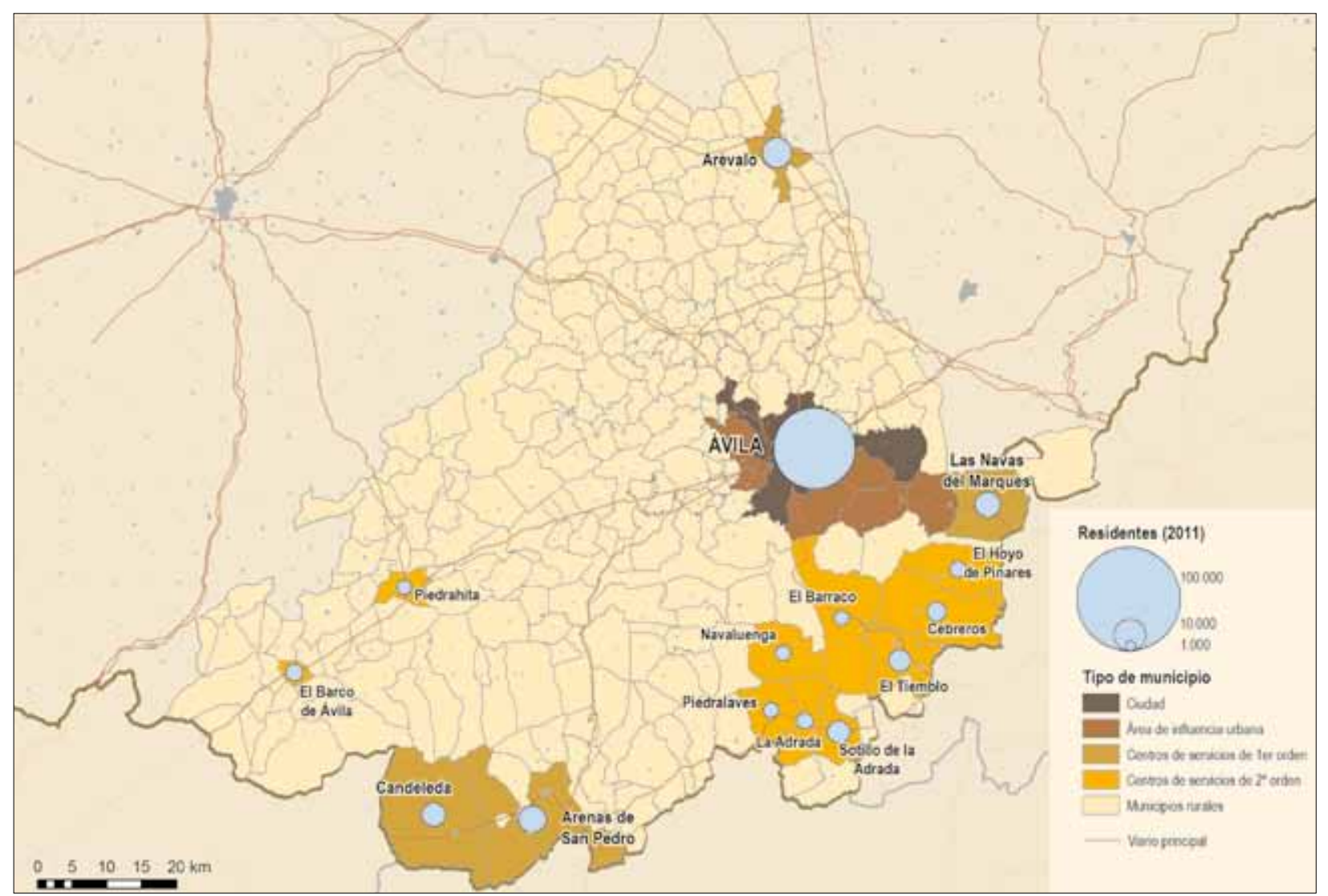

FIg. 2. Estructura territorial de la provincia de Ávila. Fuente: elaboración propia a partir de INE: Padrón municipal de habitantes.

pificados de área de influencia, en los que residen 10.554 personas más (con una ganancia 2001-2011 de 3.661), en una suerte de área urbana de tamaño intermedio, en el contexto de la comunidad. Algo menores son las magnitudes de Ponferrada, que ejerce su primacía sobre un territorio singular reconocido expresamente. Sus 68.508 habitantes han ido en aumento (5.275 en el lapso 20012011), a costa, y derivado en buena medida, de lo anterior. Por más que 11.566 personas, 1.995 a mayores en el trascurso de la década, residan en tres municipios hacia los que se canalizan algunos flujos de incrementos poblacionales consecuencia de la renta de situación. Zamora, por su parte, apenas ve variar sus cuantías padronales de los últimos años (125 vecinos menos, para un total de 65.508), conociendo al tiempo sensibles manifestaciones de difusión urbana hacia siete municipios de su área de influencia, que pasa de 5.192 a 7.369 residentes.

Ávila y Segovia se han intercambiado durante la década que acaba sus posiciones en el ranking de la jerarquía urbana. Si en 2001 Segovia cobraba ventaja con 54.039 habitantes (hoy sólo 1.181 más), Ávila lo hace ahora con 59.008 residentes (en un importante aumento de empadronamientos cuantificado en 11.041). Con todo, lo que a priori es una constatación efectiva no lo es tanto si se considera el hecho de que Segovia ha venido consolidando una importante área de crecimiento residencial al margen del municipio capitalino, que desborda hacia La Lastrilla (3.405 residentes) y otros veintidós municipios de su área de influencia (20.194 habitantes a sumar); con lo que registra un incremento poblacional de su área urbana de 9.218 personas (para un total de 78.779 residentes). Aumento, pues, similar al apuntado para la capital abulense, que cuenta, sin embargo, con una mucho menor capacidad para generar crecimientos exógenos. Análogo, en este sentido, es el caso de Soria, la capital de provincia de talla más pequeña de la comunidad (39.987 habitantes en el presente, por 34.640 en 2001), que apenas logra dinamizar un entorno en el que cuatro municipios (3.278 residentes) son los únicos en los que se constatan tímidas evidencias de influencia urbana. Como en las otras dos ciudades burgalesas de impronta industrial, Miranda de Ebro y Aranda de Duero, que vertebran parte del espacio 
provincial al norte y sur de la capital, de un tamaño y unos crecimientos recientes más o menos parejos (38.903 y 3.460 habitantes, en el caso de Miranda, y 33.229 y 3.230 para Aranda); a partir de unos entornos urbanos incipientes, de cuatro municipios en ambas, en los que residen otras 3.581 y 2.139 personas, con incrementos moderados de 1.500 y 435 habitantes.

La ciudad de Ávila viene a ocupar por número de habitantes, de esta forma, el octavo lugar en la clasificación del sistema de asentamientos de la comunidad, el noveno para ser más correctos, al considerar por entero a las áreas urbanas (ciudad media más municipios de su entorno), ya que la exigüidad residencial de los seis términos que, siguiendo la tipología del Consejo Económico y Social para el conjunto de Castilla y León, se señalan como de influencia urbana la hace bajar, en el cómputo añadido (3.224 residentes), de ese escalón (representando el caso más tímido, solo por delante de Aranda de Duero, de crecimiento rururbano) ${ }^{1}$. Unos términos municipales colindantes con el abulense muy pobres residencialmente hablando, donde exclusivamente uno supera los mil habitantes y otros dos los quinientos, en una conjunción de lábiles incrementos padronales en el trascurso del último decenio (653 habitantes más) que difieren sensiblemente, rompiendo la pauta de las áreas urbanas ya consolidadas, de la dinámica demográfica acaecida dentro de los límites del municipio capital: el segundo con mayores ganancias, tras Burgos, en términos absolutos y el de proporciones más altas de aumento del vecindario a lo largo de los primeros años dos mil $(23 \%)$ de las ciudades principales de la región.

Ávila se define como ciudad media y centro provincial. Es capital de una provincia de 8.050 kilómetros cuadrados $(8,5 \%$ de la superficie regional) en la que la diversidad, la falta de cohesión y los desequilibrios son la norma. La diversidad por su particular configuración física, de la que se derivan condiciones ecológicas contrastadas, que han condicionado, de siempre, unos modos de ocupación y de organización espaciales claramente contrastados. La falta de cohesión y los desequilibrios como lo demuestra el hecho de que 227 de los 248 municipios que parcelan la provincia (el 91,5\%) tengan menos de dos mil habitantes y sean considerados como rurales profundos. También por cuanto la capital no ha desarrollado

\footnotetext{
1 Para el CES, los municipios denominados como «área de influencia urbana» corresponden a espacios que, considerados como rurales a nivel estadístico (pues tienen menos de dos mil habitantes), mantienen un comportamiento específico inducido por la cercanía de las ciudades y su dinámica, aunque sin estar plenamente integrados en los procesos de periurbanización.
}

CUADRO II. Población residente en los centros comarcales de servicios de la provincia de Ávila, 2001-2011

\begin{tabular}{|c|c|c|}
\hline \multirow[b]{2}{*}{ Centro comarcal de servicios } & \multicolumn{2}{|c|}{ Población } \\
\hline & 2001 & 2011 \\
\hline Arévalo & 7.474 & 8.099 \\
\hline Arenas de San Pedro & 6.477 & 6.933 \\
\hline Las Navas del Marqués & 4.308 & 5.844 \\
\hline Candeleda & 5.109 & 5.213 \\
\hline Sotillo de la Adrada & 3.618 & 4.821 \\
\hline El Tiemblo & 3.625 & 4.442 \\
\hline Cebreros & 3.201 & 3.529 \\
\hline El Barco de Ávila & 2.609 & 2.729 \\
\hline La Adrada & 1.974 & 2.680 \\
\hline El Hoyo de Pinares & 2.318 & 2.422 \\
\hline Piedralaves & 2.087 & 2.298 \\
\hline Navaluenga & 2.032 & 2.190 \\
\hline El Barraco & 2.046 & 2.077 \\
\hline Piedrahíta & 2.127 & 2.014 \\
\hline TOTAL centros comarcales & 49.005 & 55.291 \\
\hline TOTAL provincial & 163.885 & 172.704 \\
\hline
\end{tabular}

Fuente: elaboración propia a partir de INE: Padrón municipal de habitantes.

un proceso de acumulación social y económica que haga gravitar en torno a sí a la totalidad del espacio que administra. Y es que ésta representa el $36 \%$ del total de habitantes provinciales, en una relación once puntos menor que la establecida para el conjunto de la comunidad, en la que, como se recordará, 47 de cada 100 residentes en ella lo hacen en una de sus doce ciudades principales. Ese papel como centro de la provincia no es tal, diluyéndose por buena parte de ella, a lo que no ayudan las distancias internas ni la anfractuosa fragmentación natural. En sectores el protagonismo recae en una serie de núcleos de tamaño intermedio, de entre dos mil y nueve mil residentes, considerados como centros de servicios a escala comarcal; catorce enclaves con gran pujanza y reafirmación en lo que a fijación del número de habitantes se refiere (6.286 más en el lapso 2001-2011), que se encuentran, eso sí, desigualmente repartidos por el mapa, lo que compromete ciertamente sus posibilidades como elementos reequilibradores de la trama territorial.

Desde Arévalo en las campiñas septentrionales (excelentemente localizado en el eje de la A-6 y del ferrocarril) al corolario de términos serranos y de allende la Sierra en el mediodía abulense (en expansión basada en el turismo, el ocio y la segunda residencia) encuadran a sus respectivas áreas rurales de referencia escapando a los influjos capitalinos. Pero es que, además, todos ellos, como por 


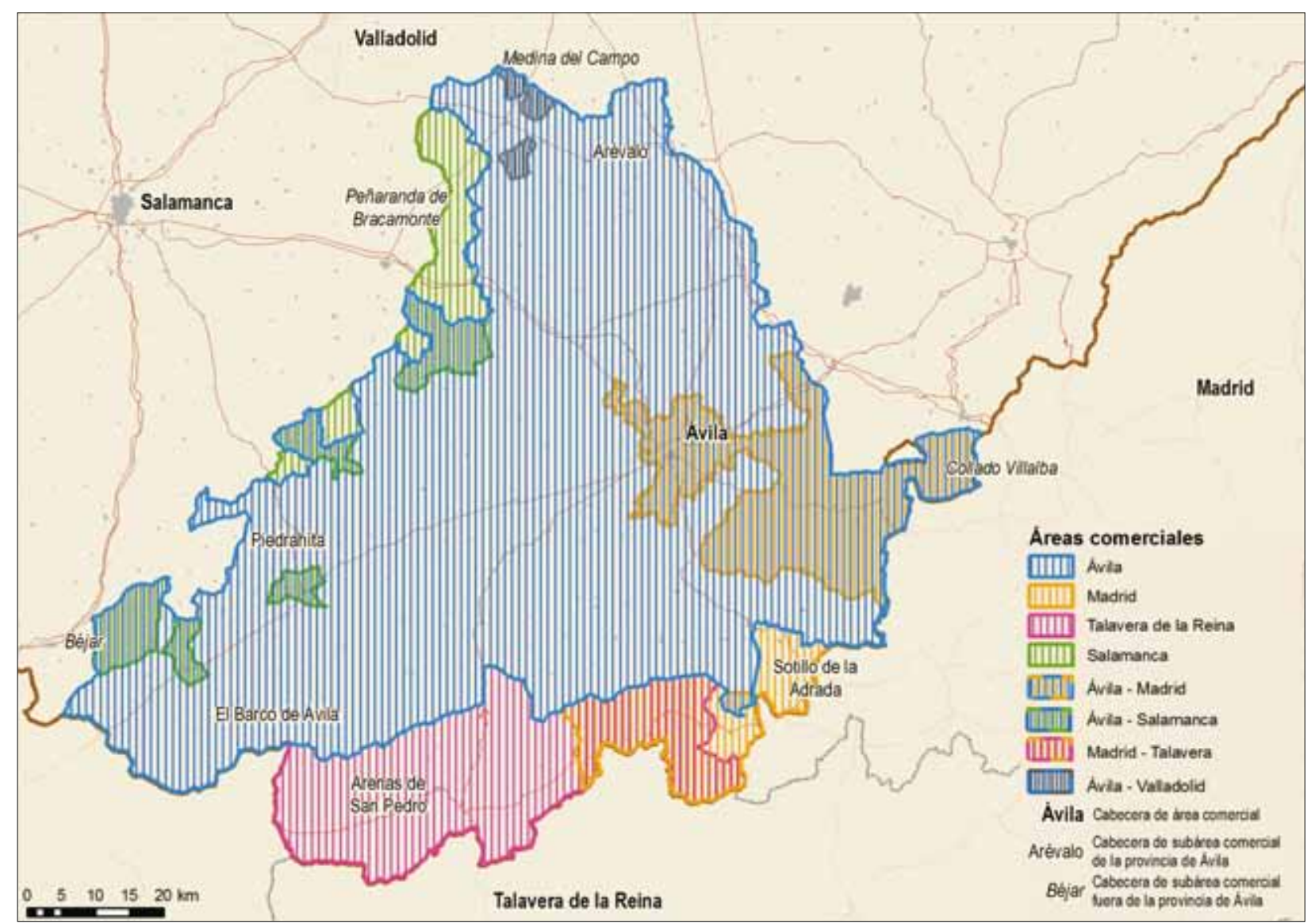

FIg. 3. Áreas de influencia comercial en la provincia de Ávila. Fuente: elaboración propia a partir de Universidad Católica de Ávila: Observatorio socioeconómico de la provincia de Ávila.

otra parte la propia capital, terminan vinculándose funcionalmente a otros espacios ajenos al marco provincial, por mor del dinamismo irradiado desde Salamanca, Talavera de la Reina o Valladolid, de manera más tenue, y de un modo sobresaliente, como ocurre con la totalidad del borde meridional castellano y leonés, se hallan bajo la dominancia de la metrópoli madrileña (3.265.038 habitantes en el municipio central y 6.489 .680 en toda su comunidad), merced al compás que marcan los intensos flujos y relaciones geográficas de todo tipo que se derivan de su posición hegemónica a escala del interior de España (Solís, 2008).

Madrid y, en menor medida, Salamanca y Valladolid (e incluso, salvando las distancias, Talavera de la Reina -88.674 habitantes -, por su competencia comercial sobre el Tiétar) son los componentes nucleares del espacio nodal en el que, finalmente, aparece insertada la ciudad de Ávila. Son los polos fundamentales que concentran a personas, mercados potenciales y a las activi- dades económicas más significativas. A partir de ellos y de sus correspondientes contornos en afianzamiento los procesos que difunden las dinámicas territoriales se canalizan a través del entramado viario conformado por las principales infraestructuras de transporte terrestre (Martínez y Luengo, 2004). La accesibilidad que da lugar a sinergias complementarias entre los distintos ámbitos y al fortalecimiento de las rentas de localización es clave para la consecución de un idóneo posicionamiento geoestratégico de Ávila.

Postergada de los trazados ferroviarios de la alta velocidad, que priorizan la conexión de la capital de España con el norte a favor de Segovia, la conectividad por tren de la capital abulense descansa en las líneas MadridÁvila-Medina del Campo-Valladolid y Ávila-Peñaranda de Bracamonte-Salamanca. La primera es todavía la que sirve de soporte a los tráficos de mercancía que se distribuyen por el cuadrante noroeste del país, sirviendo, de igual modo, a los desplazamientos «regionales» de pa- 
CUADRo III. Indicadores económicos de los núcleos principales del espacio funcional, 2011

\begin{tabular}{|c|c|c|c|c|c|}
\hline Ciudad* & Cuota de mercado & Índice industrial & Índice comercial & Índice turístico & Índice de actividad económica \\
\hline Madrid & 6.925 & 4.869 & 8.239 & 9.441 & 10.488 \\
\hline Valladolid & 668 & 884 & 840 & 429 & 795 \\
\hline Salamanca & 344 & 145 & 473 & 330 & 322 \\
\hline Talavera de la Reina & 190 & 75 & 303 & 49 & 135 \\
\hline Ávila & 130 & 104 & 135 & 134 & 120 \\
\hline \multicolumn{6}{|c|}{ "Sin contar los municipios de sus entornos periurbanos y áreas de influencia urbana. } \\
\hline \multicolumn{6}{|c|}{$\begin{array}{l}\text { La cuota de mercado es la capacidad de compra o de consumo comparativa de los municipios. Se mide en función de la cuantía y del poder } \\
\text { adquisitivo de la población. El resultado expresa la participación que corresponde a cada municipio sobre una base nacional de } 100.000 \\
\text { unidades. El índice industrial refleja el peso relativo de la industria (incluida la construcción) de un municipio respecto al total de España } \\
\text { ( } 100.000 \text { unidades). El índice comercial manifiesta la participación de la actividad comercial municipal en relación al conjunto del país } \\
\text { (100.000 unidades). El índice turístico hace lo propio con las actividades turísticas, sobre una base nacional de } 100.000 \text { unidades. Por } \\
\text { último, el índice de actividades económicas engloba al total de actividades económicas (excluidas las agrarias), igualmente sobre la base } \\
\text { española de } 100.000 \text { unidades. }\end{array}$} \\
\hline
\end{tabular}

Fuente: La Caixa: Anuario económico de España 2012.

sajeros en unos viajes que con una duración de entre una hora y diez minutos y una hora y media ponen en relación la capital abulense con Madrid y Valladolid. En similares tiempos de duración que el trayecto que une a Ávila con Salamanca ${ }^{2}$.

Mayor relevancia, si cabe, al ser la red de carreteras la base del sistema de movilidad, adquiere la posibilidad de enlazar rápidamente con Madrid y Salamanca (115 y $97 \mathrm{~km}$ en $1 \mathrm{~h} 20^{\prime}$ y $1 \mathrm{~h} 10^{\prime}$, aproximadamente) a través de la puesta en funcionamiento de dos nuevos viales de alta capacidad como son la autopista de peaje AP-51 (Ávila-Villacastín) ${ }^{3}$, paralela a la N-110, y la autovía A-50 (Ávila-Salamanca). No ocurre lo mismo con respecto a Valladolid, manteniéndose el tradicional camino (vía Adanero) de la N-403 y su entronque con la N-601, sin posibilidad por el momento de reducir los tiempos de viaje $(121 \mathrm{~km})$ por debajo de la hora y cuarenta minutos ${ }^{4}$. Un viario convencional de la RIGE que se mantiene para la articulación de los tránsitos hacia Plasencia (N-110), Talavera de la Reina (N-502) y Toledo (N-403) (o Madrid,

\footnotetext{
${ }^{2}$ En el marco del plan de racionalización de los servicios ferroviarios desarrollado por el Ministerio de Fomento, Renfe modificó, a partir del 2 de junio de 2013, los servicios de media distancia convencional en Castilla y León, lo que afecta con pérdidas de frecuencia a las líneas Madrid-Ávila y Ávila-Valladolid. Sin embargo, se mantiene el servicio diario en ambos sentidos entre Ávila y Salamanca, tras la decisión de Ayuntamiento y Diputación de sufragar parte del coste de su funcionamiento.

3 Según datos facilitados por el Grupo Abertis, propietario de las concesionarias Castellana de Autopistas e Iberpistas, la tarifa normal para 2014 incluyendo los tramos Ávila-Villacastín y Villacastín-Villalba (AP-6) es de 9,35 euros.

${ }^{4}$ Duración muy similar a la de la ruta alternativa que desde Adanero conecta con Tordesillas, siguiendo la A-6, en su enlace con la A-62 a Valladolid (140 km).
}

vía San Martín de Valdeiglesias), completado en este orden superior por la autonómica de primer nivel a San Lorenzo de El Escorial (CL-505), de vital importancia también al poner en comunicación la capital de la provincia con buena parte de los centros de raigambre comarcal al sur de ésta, si bien en unos tiempos medios de viaje muy ralentizados por la compartimentación espacial en diferentes unidades de relieve desniveladas en puertos.

\section{El TERRITORIO MUNICIPAL: NATURALEZA Y RURALIDAD COMO CLAVES DE LA DIVERSIDAD DE UN ENTORNO ESCASAMENTE URBANIZADO}

El término municipal de Ávila tiene una superficie de 231,9 kilómetros cuadrados. Es el municipio de mayores dimensiones de todos cuantos componen la provincia (el $2,9 \%$ de su extensión). Por su localización y envergadura participa, a grandes rasgos, y en mayor o menor media, de los dos principales ámbitos naturales que caracterizan a esta. Pocos kilómetros al norte, en torno a Mingorría (la falla de Mingorría, de orientación SO-NE, pone en contacto a los materiales sedimentarios de la Cuenca con el roquedo granítico del Macizo Antiguo, en el sector que nos ocupa), se entra de lleno en el dominio de la Tierra Llana, excelsa campiña de ondulados horizontes que marca los trazos de los paisajes provinciales en su tercio septentrional. En su margen, el espacio municipal se enmarca dentro del dilatado y quebrado conjunto montañoso meridional, y más concretamente en varias de las morfoestructuras en las que éste aparece desgajado. En 


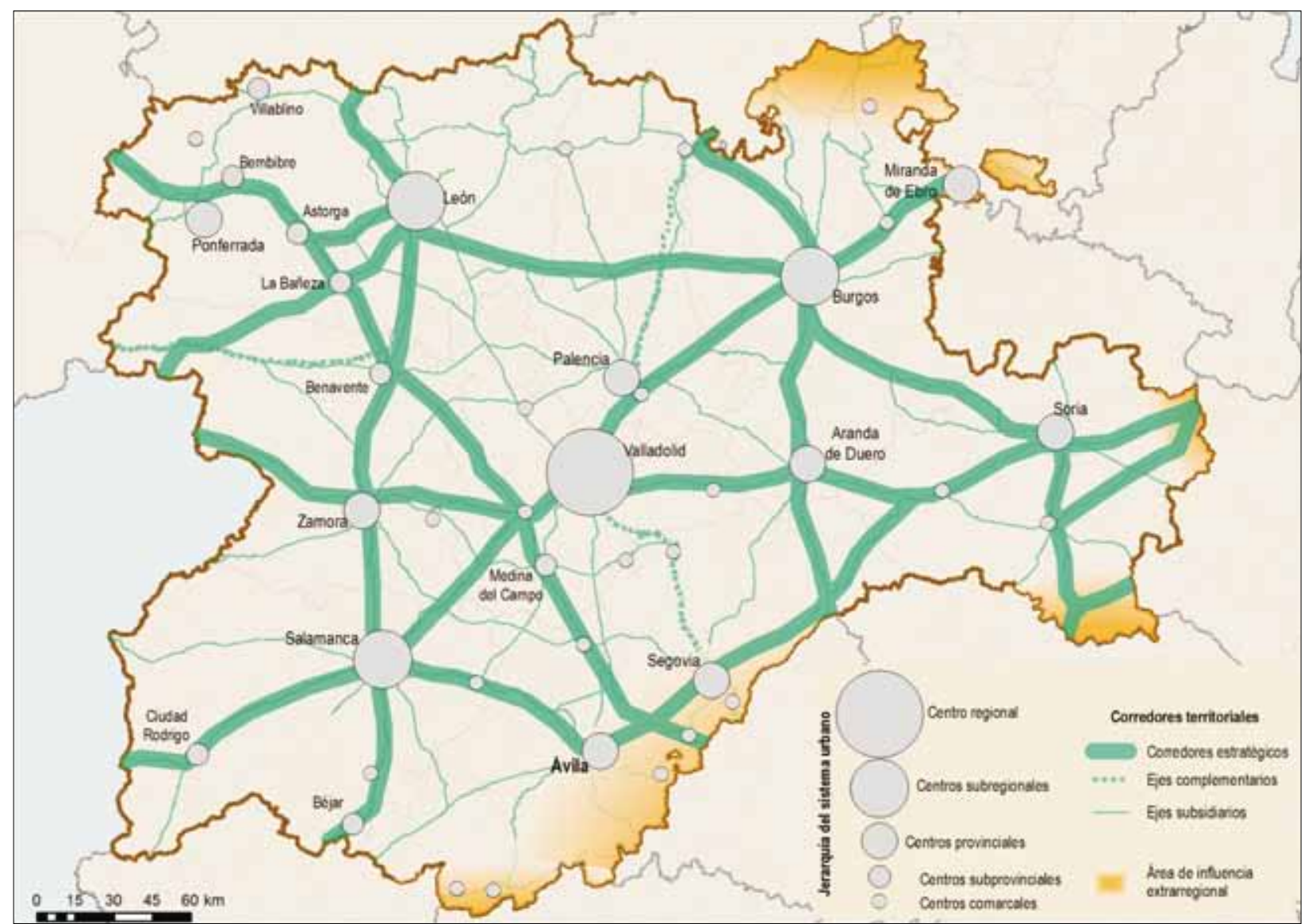

Fig. 4. Núcleos funcionales y elementos estructurantes del territorio. Fuente: elaboración propia.

altitudes que oscilan entre los 975 y los 1.540 metros, desde la entalladura del Adaja al alto de Casasola, en el término se suceden distintas unidades de relieve, a modo de segmentos cuarteados del zócalo berroqueño en juego de bloques de fractura, dispuestas en fajas más o menos planas (áreas de llanura) y escalonadas al contacto con los rebordes serranos. La sierra de Ávila, en su apófisis oriental, es el primero de estos roldes circundantes. Se trata de un bloque (horst) levantado de disposición SO-NE, en una traza que viene marcada por la línea de debilidad tectónica mencionada, que corresponde con la primera de las tres alineaciones paralelas de la Cordillera Central en su tramo central abulense. Más a levante, y $\sin$ apenas discontinuidades aparentes en lo litológico y estructural, que sí en lo topográfico, se abre la rampa de piedemonte Ávila-Villacastín, de cuya «penillanura» de dominantes superficies de erosión y modelados graníticos (berrocales) participa la fracción nororiental del espacio físico del municipio. En su interior, encuadrada por la sierra de Ávila y por La Paramera (la sierra de Yemas como antesala), al mediodía, la fosa de Amblés constituye el elemento bisagra. Corresponde a una considerable dovela de zócalo hundida (graben) que da lugar a un amplio valle en artesa de fondo plano, en el que las rocas cristalinas del Paleozoico se hallan tapizadas en cientos de metros de espesor por sedimentos terciarios y cuaternarios apenas incididos por la red fluvial del Adaja; quedando en resalte el promontorio granitoide sobre el que se desarrolla la propia ciudad (que a 1.131 metros de altitud es la capital de provincia más elevada de España). Ella se ubica, por tanto, a caballo del valle y de la peniaplanada plataforma estructural que la enrasa. Y que enlaza sin solución de continuidad, en los confines levantinos del municipio, con el valle que drenado por el río Voltoya se adapta a la cubeta menor del Campo Azálvaro, de orientación tardihercínica E-O al igual que las sierras masivamente metamórficas (pizarras y cuarcitas) y de perfil menos romo que lo individualizan: la de Ojos 


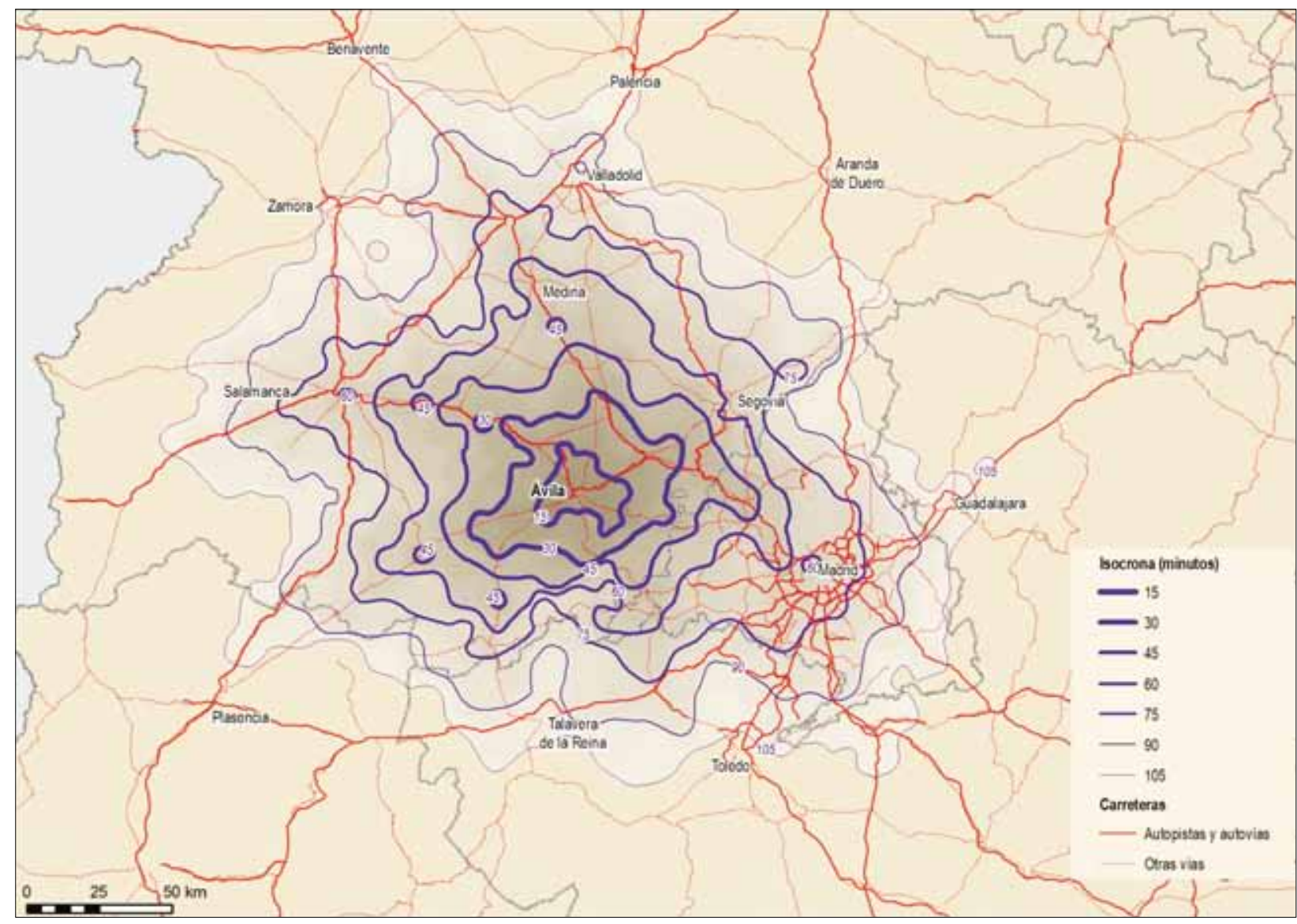

FIg. 5. Accesibilidad por carretera de la ciudad de Ávila mediante isócronas. Fuente: elaboración propia a partir de tiempos de desplazamiento mediante GPS.

Albos, al norte, y la de Malagón, al sur.

La estructura territorial que descansa sobre esta malla geomorfológica, y más allá de la propia ciudad que le confiere un carácter netamente urbano al municipio, se articula en función de una serie de núcleos de tamaño demográfico reducido, de entre 24 y 282 habitantes, de tendencias contrapuestas a lo largo del último decenio, en una tónica de estancamiento general (27 personas más entre 2001 y 2011) que contrasta con las pérdidas de décadas atrás, y que apenas suman el 1,4\% de los residentes en el término. Se trata de entidades incorporadas a la administración local abulense entre 1976 y 1977, cuya modestia poblacional, mitigada por la renovación del caserío, la proliferación residencial en parcelas individuales, algunas de uso principal ya, e incluso por la instalación de equipamientos de ocio (Naturávila), de servicios (centro penitenciario de Brieva) o industriales (polígono de Vicolozano), no es óbice para ensalzar el protago- nismo que adquieren como componentes esenciales en la organización del espacio rural que circunda a la ciudad.

De este modo, cada uno de estos enclaves ordena a su alrededor los predios agrarios y forestales de una porción destacada del término municipal. En la media montaña de vocación más ganadera y usos pratenses (estribaciones de la sierra de Ávila) se ubican Alamedilla del Berrocal y Narrillos de San Leonardo. Las llanuras más lígrimas sobre los litosuelos del piedemonte noreste, parcelados en pagos de montes huecos, dehesas y pastos, sirven de asiento a Brieva, Vicolozano, Bernuy-Salinero y, en plena transición al Campo Azálvaro, Urraca-Miguel. Finalmente, Aldea del Rey Niño (en el arranque de la sierra de Yemas) y la propia ciudad concentran, situadas por la fosa de Amblés, a las tierras de cultivo de mayor predicamento y productividad, sobre los suelos más evolucionados de los fondos de valle.

Un espacio rústico en franca decadencia y retroceso, 


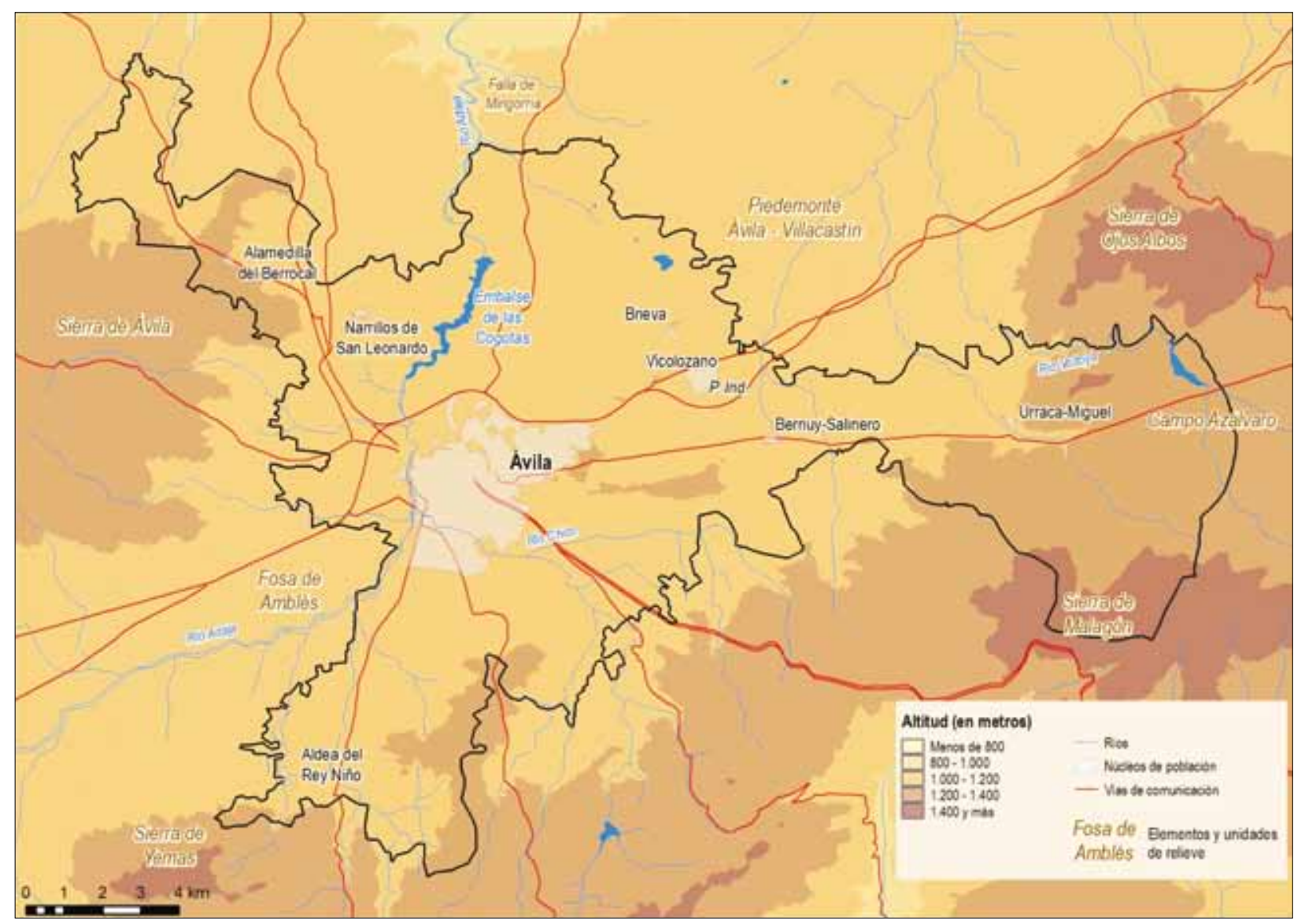

FIG. 6. Estructura territorial del municipio de Ávila. Fuente: elaboración propia.

como lo atestiguan sin freno el aumento de las tierras baldías, los barbechos y la expansión del matorral (además de la languidez de unos datos que hablan de que un escaso $1,3 \%$ de los ocupados en el municipio - por el 9,8 de la provincia, o el 7,3 de Castilla y León- son agrarios), en el que se intercalan por doquier los retazos de naturalidad en forma de promiscuos salientes rocosos o de valores ecológicos atesorados por las vestes forestales propias del dominio mediterráneo de interior: encinares y más raramente rebollares conforme aumenta la altitud, mejor conservadas; y por, aparte de algunas manchas repobladas de pinar, los sotos ribereños (El Soto) que jalonan cuales cintas arboladas los cursos de agua. En definitiva, un verdadero mosaico de usos del suelo en el que sobresalen los pastos como superficies predominantes, en una gradación de modalidades, según la intensidad en el aprovechamiento de los mismos, que va desde aquellos más marginales, menos accesibles y abandonados progresivamente al albur de la colonización arbustiva, a los mejor dispuestos para el alimento del ganado vacuno, ovino y caprino en régimen extensivo, pasando por los que se desarrollan entre masas arbóreas (dehesas y montes adehesados), pastados a diente por una floreciente cabaña bovina de razas autóctonas (avileña y, en menor medida, morucha), cuyas producciones de calidad se amparan bajo la imagen de marca de la Indicación Geográfica Protegida Carne de Ávila ${ }^{5}$. A gran distancia en lo que a extensión de los paisajes campesinos se refiere, las tierras de cultivo, esencialmente secanos cerealistas con algún pago menor de regadío forrajero, huertas, invernaderos y plantaciones de frutal. Una muestra, en suma, de la riqueza y diversidad de un entorno en el que el piélago de la ruralidad y la naturaleza más o menos intervenida es contraste y complemento de la ciudad, de su trama

\footnotetext{
${ }^{5}$ Sobre este aspecto tan particular, puede consultarse $<$ www.carnedeavila.org $>$.
} 
CUADRo IV. Entidades de población del término municipal de Ávila

\begin{tabular}{|c|c|c|c|}
\hline Entidad singular & Núcleo de población & Población 2001 & Población 2011 \\
\hline \multirow[t]{2}{*}{ Alamedilla del BerRocal } & Alamedilla del Berrocal & 63 & 93 \\
\hline & Aldea del Rey Niño & 399 & 282 \\
\hline \multirow{2}{*}{ AldeA Del Rey NiÑo } & Diseminado & 0 & 0 \\
\hline & Ávila & 47.197 & 58.211 \\
\hline Ávila & Diseminado & 0 & 43 \\
\hline \multirow{2}{*}{ BERNUY-SALINERo } & Bernuy-Salinero & 42 & 24 \\
\hline & Brieva & 0 & 37 \\
\hline BRIEVA-VICOLOZANO & Vicolozano & 79 & 77 \\
\hline NARRILLOS DE SAN LEONARDO & Narrillos de San Leonardo & 114 & 186 \\
\hline URRACA-Miguel & Urraca-Miguel & 73 & 55 \\
\hline Total municipio & - & 47.967 & 59.008 \\
\hline \multicolumn{4}{|c|}{$\begin{array}{l}\text { Se denomina «entidad singular de población» a cualquier área habitada de un término municipal claramente di- } \\
\text { ferenciada dentro del mismo y que es conocida por una denominación específica que la identifica sin posibilidad } \\
\text { de confusión. Estas entidades singulares pueden estar constituidas por uno o varios núcleos de población, o por } \\
\text { diseminados que engloban a las edificaciones o viviendas que no pueden incluirse en el concepto de núcleo. }\end{array}$} \\
\hline
\end{tabular}

Fuente: INE: Nomenclátor de entidades de población.

urbana y su actividad (Ezquiaga, 2006).

\section{UN COMPACTO ENTRAMADO URBANO: EVOLUCIÓN DE LA POBLACIÓN Y DESARROLLO RESIDENCIAL}

\author{
1. La estructura uRbana de Ávila \\ Y SU EVOLUCIÓN AL COMPÁS DEL DINAMISMO \\ DEMOGRÁFICO DE LOS ÚLTIMOS SESENTA AÑOS
}

La organización del entramado urbano de Ávila se define a partir de un «centro» paulatinamente alargado y desplazado hacia el este ${ }^{6}$, que puede ser identificado con la ciudad histórica (Villar, 1982 y 1984). Dentro ella se diferenciaban claramente una serie de espacios más o menos contiguos: el centro-intramuros, verdadero elemento original dentro del recinto amurallado, con su casalicio apiñado sobre las abigarradas calles, y una orla completa de arrabales (Cuatro Postes, San Nicolás, Las Vacas, Extramuros) como evidencias de las primeras expansiones, de misma raíz medieval, del tejido construido. Atraída por el ferrocarril, la ciudad burguesa apenas se

\footnotetext{
${ }^{6}$ Que se prolonga desde la plaza del Chico (Mercado Chico) a la de Santa Ana a través del nodo del Grande (Mercado Grande), más la rama colateral de la avenida de Portugal.
}

desarrollará por el frente oriental (San Roque), a favor de los bonancibles condicionamientos topográficos de la superficie de erosión berroqueña. Esta contenida configuración, a lo largo del tiempo, sufrió una gran transformación desde el momento en el que la ciudad comenzó a experimentar un incremento sustancial de la población. Fue entonces, al comedio del siglo xx, cuando comenzaron las ampliaciones progresivas y la edificación de nuevos terrenos, cada vez más alejados, destinados a satisfacer la creciente demanda residencial.

$\mathrm{Si}$ en la ciudad histórica, aquejada intensamente por los procesos de abandono comunes a los centros urbanos españoles, la modificación más sustancial será la ocupación selectiva de los escasos espacios que van quedando libres (huertas conventuales, jardines o corrales privados) y la sustitución, renovación, restauración o rehabilitación en su caso, muy parcial, de las bajas edificaciones precedentes por modernos edificios en altura (mediatizados en lo posible por la restricción de volúmenes y la adaptación a la fisonomía del entorno), la cuantiosa necesidad habitacional registrada en la capital se resolverá, en una primera fase, hasta bien entrada la década de 1970, con la aparición de los nuevos barrios inmediatos a aquélla (y su característica tipología constructiva plurifamiliar en bloques o manzanas abiertas, en alturas de tres y cuatro plantas).

De esta forma, prosiguiendo con el sentido natural en el agrandamiento del solar urbano hacia levante, evitando en lo posible el obstáculo fluvial y los pendientes 


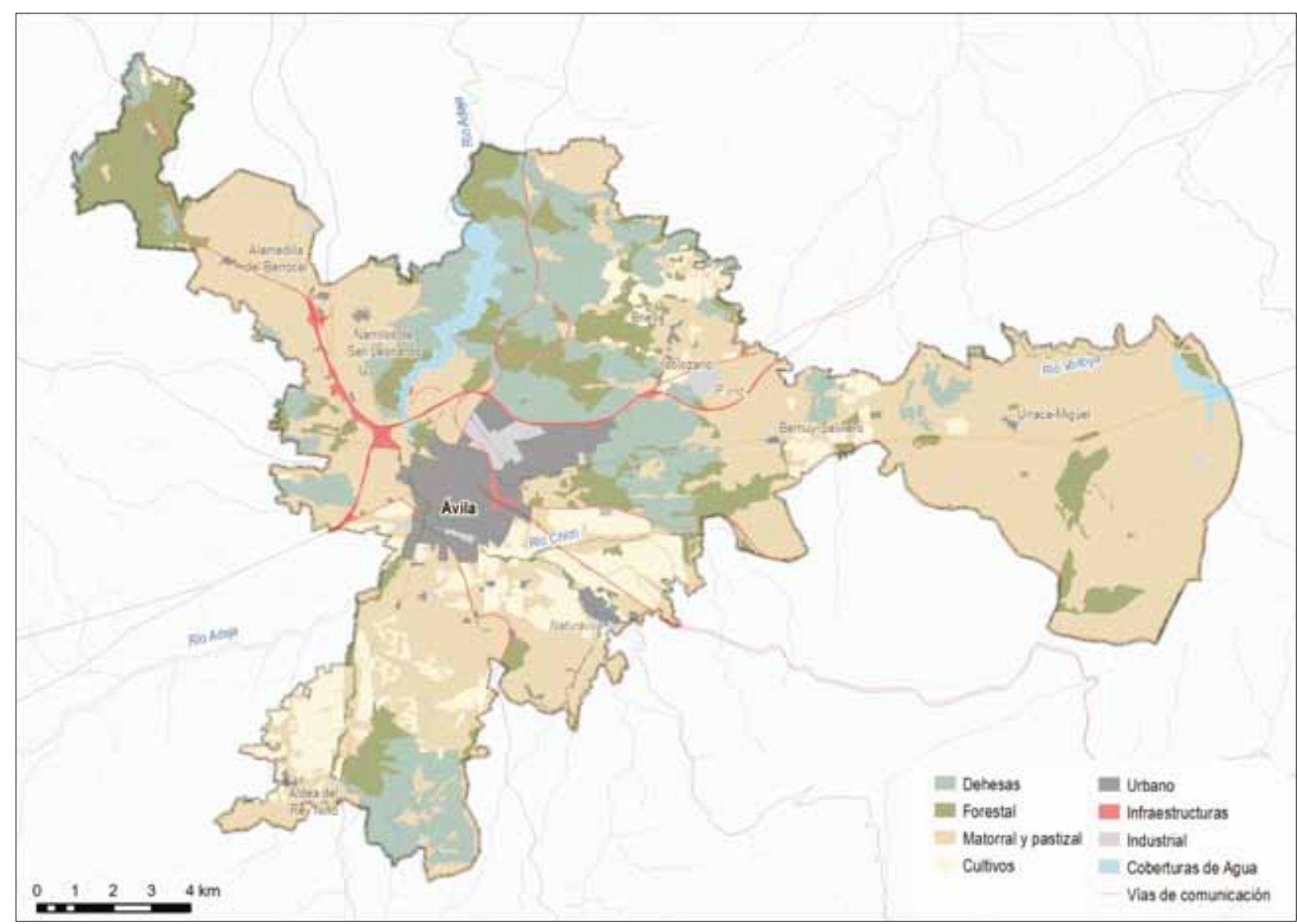

FIG. 7. Usos del suelo en el término municipal de Ávila. Fuente: elaboración propia a partir de IGN y CNIG: SIOSE (Sistema de Información sobre Ocupación del Suelo de España).

escarpes del mediodía, al mismo tiempo que se preservan las más valoradas panorámicas de las murallas y su perímetro de lienzo y torres, y hasta llegar a las vías del tren, auténticas barreras para la continuación del desarrollo en este sector, irán surgiendo, o completando su incipiente crecimiento previo, dando acomodo a los relevantes aumentos del vecindario de la época (7.946 y 8.639 habitantes entre 1950 y 1970 y de 1970 y 1981 , respectivamente), los barrios de San Antonio-Estación y Santo Tomás. Más lentamente será abierto un nuevo sector de expansión urbana en el sur (con origen en La Toledana y el mismo Santo Tomás), ya en el fondo de la fosa tectónica y más allá del arrabal de San Nicolás (muy remozado $^{7}$, que se irá dinamizando hacia el valle del río Chico a medida que se van agotando las posibilidades del

\footnotetext{
${ }^{7}$ Antesala de la ocupación del flanco meridional sobre el valle de Amblés, de orientación solana y proximidad al rico labradío de la urbe.
}

avance oriental; y que se erige desde los años ochentanoventa en la porción urbana que concentra los polígonos residenciales de mayor dinamismo: Valle AmblésUniversidad; soportando en gran medida los incrementos demográficos más notables (7.794 residentes entre 1981 y 2001 y 11.041 más hasta 2011), en una suerte de modernos ensanches de morfología reticular, con elementos residenciales de densidad media en manzana cerrada o bloque, en las proximidades de varios de los principales equipamientos de la capital (plaza de toros, estadio municipal, hipermercado, hospital provincial, psiquiátrico, escuelas universitaria y politécnica de la Universidad de Salamanca).

En el extremo contrario, a septentrión, la evolución constructiva de las dos últimas décadas también ha alcanzado al valle del arroyo de Las Pozas, una suave vaguada en la plataforma estructural, que dilata las piezas heredadas de San Antonio-La Cacharra-Encarnación, y que, encorsetado hacia el norte por la línea férrea a Sala- 


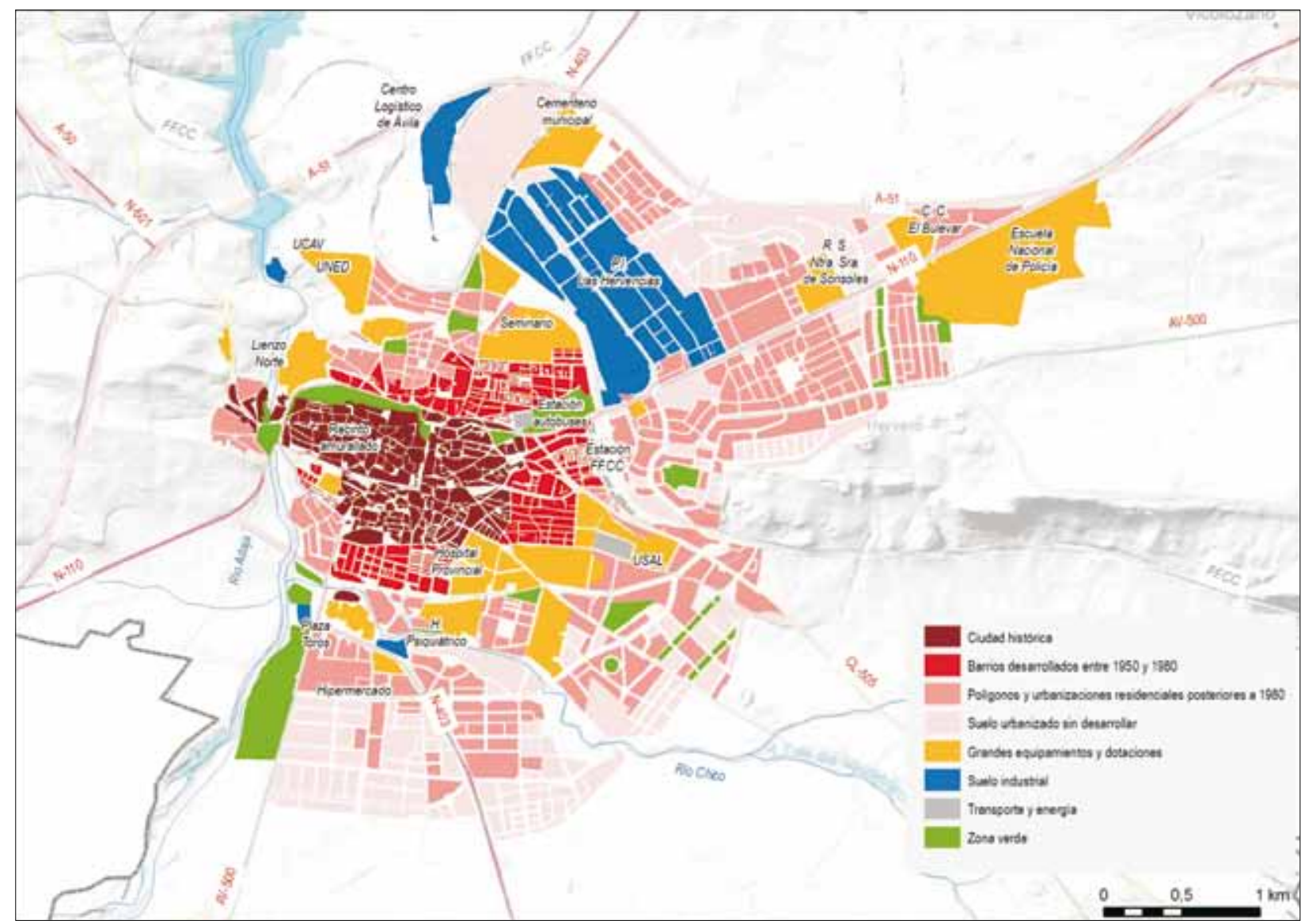

FIg. 8. Crecimiento y estructura urbana de Ávila. Fuente: elaboración propia.

manca, dibuja unas zonas de baja edificabilidad en torno al Seminario y a la Universidad Católica de Ávila y el Centro Asociado de la unED, donde el adosado ha sido el tipo constructivo predominante. Similares tipologías de residencia unifamiliar en hilera, adosadas o aisladas, se han levantado coetáneamente en algunas urbanizaciones que han ido estirando considerablemente los bordes de la ciudad (téngase en cuenta que 3.320 edificios destinados a vivienda se construyeron entre 1991 y 2011, el $41,4 \%$ de todos los existentes). Una de menor extensión es la aparecida en la otra orilla del Adaja, con vistas al núcleo amurallado. Pero la más significativa es la de Las Hervencias, en la carretera de Villacastín, allende la barrera del ferrocarril y del homónimo polígono industrial de específica localización al lado de la fábrica de Nissan, y cercana a la Residencia Sanitaria Nuestra Señora de Sonsoles, a la Escuela Nacional de Policía y al centro comercial El Bulevar.

\section{LA CIUDAD Y SU DIFERENCIACIÓN GEODEMOGRÁFICA}

La positiva evolución demográfica experimentada por Ávila durante el último decenio examinado, en visos de ralentización o ligero decrecimiento actual $(93$ empadronados menos en el término durante el lapso 20112012), solamente puede ser explicada, en el marco de la dinámica expansiva conocida por todas las áreas urbanas de Castilla y León, por el aumento del número de residentes en la ciudad compacta, sin, como se comentó, contar con ningún municipio periurbano de sobresaliente dinamismo como para absorber en torno a sí las intensas pulsaciones poblacionales conocidas en los primeros años dos $\mathrm{mil}^{8}$. Así, con ausencia de crecimientos exóge-

${ }^{8}$ Ya fue citado el hecho de que Ávila, tras Burgos, es la ciudad de la comunidad autónoma que ha registrado un mayor incremento de población (la que más en términos relativos) entre 2001 y 2011. Con todo, este importante aumento habitacional no es tan destacado dentro del conjunto de las áreas urbanas (ciudad 
CuAdro V. Evolución de la población residente en el municipio de Ávila, 1950 a 2012

$\frac{1950}{23.588} \frac{1960}{28.032} \frac{1970}{31.534} \frac{1981}{40.173} \frac{1991}{45.977} \frac{2001}{47.967} \frac{2011}{59.008} \frac{2012}{58.915}$

Fuente: INE: Censo de población y viviendas (hasta 1991) y Padrón municipal de habitantes.

Cuadro VI. Número de edificios destinados a vivienda en Ávila por etapa de construcción

\begin{tabular}{|c|c|c|c|c|c|c|c|}
\hline Antes de 1950 & Años 50 & Años 60 & Años 70 & Años 80 & Años 90 & Años 2000 & Total edificios \\
\hline 1.035 & 934 & 621 & 1.182 & 928 & 1.036 & 2.284 & 8.020 \\
\hline
\end{tabular}

Fuente: INE: Censo de población y viviendas.

Cuadro VII. Distribución de la población por los diferentes sectores urbanos de la ciudad de Ávila*, 2004-2012

\begin{tabular}{|c|c|c|}
\hline Sector urbano & Población 2004 & Población 2012 \\
\hline Sector 1. Intramuros y Cuatro Postes & 3.263 & 3.062 \\
\hline Sector 2. Extramuros & 3.409 & 3.077 \\
\hline Sector 3. Encarnación & 3.376 & 3.435 \\
\hline Sector 4. San Nicolás-Las Vacas-La Toledana-Valle Amblés & 17.300 & 18.948 \\
\hline Sector 5. Santo Tomás-Universidad & 8.683 & 10.975 \\
\hline Sector 6. La Cacharra-San Antonio-Estación-Las Hervencias & 15.648 & 18.688 \\
\hline TOTAL & 51.679 & 58.185 \\
\hline
\end{tabular}

Fuente: elaboración propia a partir de Ayuntamiento de Ávila: Explotación estadística del Padrón municipal.

nos de entidad, la capital se desarrollará enormemente en un proceso de ampliación del espacio construido cuyo soporte estratégico se ha fundamentado, además, en la dialéctica establecida entre el centro y la periferia.

Bajo estas pautas, que han caracterizado a Ávila a lo largo de estos diez años finales, se esconden comportamientos muy variables entre los diferentes sectores urbanos que la componen, tanto desde el punto de vista de su evolución y cuantía residencial como de sus principales estructuras de población, en particular las etarias.

En un ejercicio de erudición no exento de riesgos y de limitaciones fruto de la utilización de las unidades estadísticas al uso (distritos y secciones) en la división de los principales segmentos de la ciudad, al hilo también del análisis efectuado sobre la configuración de la misma por la sucesiva adición de las áreas-barrios mencionados, que

y entorno urbano) castellanas y leonesas, situándose en el quinto puesto, en la línea del acontecido, por ejemplo, en otra de similar jerarquía: Segovia (1.181 residentes más, pero 9.087 a sumar por los municipios de su dinámico contorno de influencia). son los comúnmente identificados por los abulenses, seis son las grandes teselas que conforman el espacio urbano de la capital. Dos puede decirse que corresponden estrictamente al «centro» (la ciudad histórica dentro de las murallas y los primigenios arrabales de Extramuros). Los arrabales más alejados de aquélla y los barrios que se van adosando durante la etapa del desarrollismo quedan enmarcados como piezas originales en el resto de las zonas. Prima en ellas, pues, una distinción laxa siguiendo exclusivamente un criterio censal de localización, tamaño y proximidad al núcleo central: al norte y sur, respectivamente, Encarnación y el variopinto conjunto de San Nicolás-Las Vacas-La Toledana-Valle Amblés. Y más alejadas las misceláneas áreas de Santo Tomás-Universidad, en continuación de la anterior hacia el sureste y, haciendo lo propio en el noreste con la primera de éstas, La Cacharra-San Antonio-Estación-Las Hervencias.

La importante capacidad de crecimiento residencial de Ávila en el pasado más inmediato se ha manifestado, en parigual, y como no podía ser de otra manera, en la ampliación del número de secciones censales en los más 


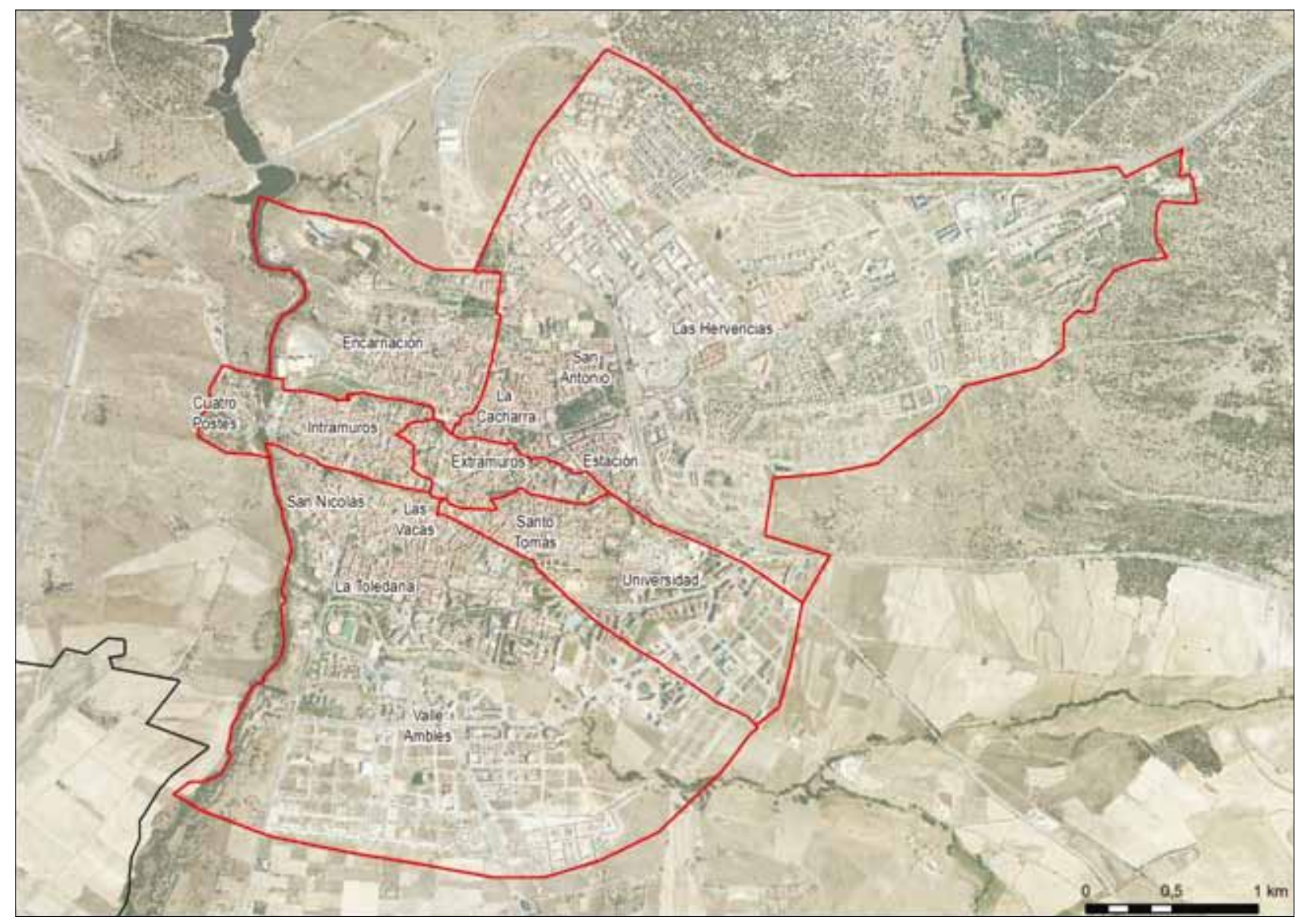

FIG. 9. Sectores urbanos de la ciudad de Ávila. Fuente: elaboración propia a partir de IGN y CNIG: CartoCiudad (sistema de información de la red viaria, cartografía urbana y divisiones censal y postal de España).

pujantes de estos distritos. No en vano, a las porciones del Valle Amblés, Universidad y Las Hervencias les han correspondido tres, una y dos, por este orden, nuevas unidades censales. Extensión de los polígonos y urbanizaciones en los sectores de la ciudad más alejados como prueba fehaciente del impulso sobresaliente en los cómputos de población registrados; empero muestra palmaria, no debe obviarse tal circunstancia, de la coexistencia de una serie de fenómenos urbanísticos contradictorios, a través de los cuales se materializan los mecanismos básicos de intervención y creación de ciudad en la actualidad (Calderón, 2001).

El primero de estos procesos, dilatado en el tiempo, pero de todavía notable intensidad en nuestros días, ha sido el del progresivo abandono y vaciamiento del centro histórico, que deja de ser un ámbito de atractivo residencial, como lo atestigua la perenne reducción de sus vecindarios. Si circunscribiendo el apunte al balance
2004-2012 viven en el conjunto del entramado «medieval» 6.139 personas (el 10,5\% de todos los abulenses), éstos continúan mermando en 533. Éste es un fenómeno ininterrumpido prácticamente desde el mismo momento en el que Ávila comienza a agrandarse mediada la anterior centuria. La especialización funcional, la ausencia significativa de espacios libres y las dificultades y trabas (por ausencia de intereses inmobiliarios o de restricciones formales) para la sustitución o renovación del viejo casalicio son las explicaciones más argumentadas 9 . Otro

${ }^{9}$ La creciente terciarización y recualificación de las funciones tradicionales del centro histórico, cada vez más impregnado de una cultura museística que pretende hacer de él una ciudad-patrimonio para el turista, la ausencia de una adecuada política pública de recuperación del tejido edificado, que pudiera paliar el estado lamentable en el que se encuentran muchos de los inmuebles, y la carencia de inversión privada, que hace que las escasas viviendas renovadas o rehabilitadas alcancen precios astronómicos, acaban erigiéndose como los factores explicativos de la pérdida de importancia residencial del «centro» (Villar, 1999). 
CuAdro VIII. Principales indicadores de estructuras demográficas por edad y sector urbano en Ávila capital, 2012

\begin{tabular}{|c|c|c|c|c|c|c|c|}
\hline $\begin{array}{l}\text { Sector } \\
\text { urbano }\end{array}$ & $\begin{array}{c}\text { Índice de } \\
\text { envejecimiento }\end{array}$ & $\begin{array}{c}\text { Tasa de } \\
\text { envejecimiento }\end{array}$ & $\begin{array}{c}\text { Tasa de sobre } \\
\text { envejecimiento }\end{array}$ & $\begin{array}{c}\% \text { de } \\
\text { octogenarios }\end{array}$ & $\begin{array}{l}\text { Edad } \\
\text { media }\end{array}$ & $\begin{array}{c}\text { Proporción } \\
\text { de activos }\end{array}$ & $\begin{array}{c}\text { Índice de reemplazo } \\
\text { de activos }\end{array}$ \\
\hline Sector 1 & 1,59 & 20,53 & 34,06 & 6,99 & 44,46 & 66,54 & 0,89 \\
\hline Sector 2 & 2,67 & 30,55 & 36,06 & 11,02 & 48,76 & 58,01 & 0,66 \\
\hline Sector 3 & 0,71 & 11,61 & 22,57 & 2,62 & 39,99 & 71,95 & 1,16 \\
\hline Sector 4 & 0,97 & 15,58 & 32,82 & 5,11 & 40,73 & 68,28 & 1,41 \\
\hline Sector 5 & 0,91 & 14,58 & 31,81 & 4,64 & 39,94 & 69,38 & 0,90 \\
\hline Sector 6 & 1,10 & 17,94 & 35,07 & 6,29 & 41,99 & 65,78 & 0,84 \\
\hline Ávila capital & 1,08 & 16,95 & 33,37 & 5,66 & 41,63 & 67,29 & 1,03 \\
\hline \multicolumn{8}{|c|}{$\begin{array}{l}\text { Índice de envejecimiento: cociente entre la población de } 65 \text { y más años y la población menor de 16; Tasa de envejecimiento: \% de población } \\
\text { de } 65 \text { y más años respecto a la población total; Tasa de sobre envejecimiento: \% de población de } 80 \text { y más años respecto a la población de } \\
65 \text { años y más; \% de octogenarios: porcentaje de población de } 80 \text { y más años respecto a la población total; Proporción de activos: \% de } \\
\text { población de } 16 \text { a } 64 \text { años respecto a la población total; Índice de reemplazo de activos: cociente entre la población de } 15 \text { a } 19 \text { años y la } \\
\text { población de } 60 \text { a } 64 \text { años. }\end{array}$} \\
\hline
\end{tabular}

Fuente: elaboración propia a partir de INE: Padrón municipal de habitantes y Ayuntamiento de Ávila: Explotación estadística del Padrón municipal.

tanto ocurre en los arrabales y barrios populares desarrollados al ritmo de los fuertes incrementos demográficos de las décadas de 1950 y 1970. En ellos, las causas del abandono deben buscarse en factores como la insuficiencia de infraestructuras y equipamientos dotacionales o la peor calidad de las viviendas, ubicadas por lo general en edificios que han cumplido un ciclo de 45-60 años.

La salida del hogar paterno, la mejora del nivel de vida de la población madura-joven en los años previos a la crisis y las nuevas modas y pautas residenciales acaban por explicar la búsqueda de nuevos espacios donde vivir. Aun así, estos sectores más apegados al casco histórico todavía aglutinan a un alto porcentaje de los habitantes de la capital, si bien los datos concretos son difíciles de precisar en una valoración de conjunto como la realizada ${ }^{10}$; erigiéndose, al tiempo, en lugares de acogida preferente para la nada desdeñable inmigración extranjera $(9,7 \%$ de los habitantes de la ciudad).

Frente al descenso generalizado de población en la ciudad tradicional y barrios aledaños, en un contexto de evidente afianzamiento demográfico de Ávila, el crecimiento urbano periférico (que en el caso abulense refuerza el modelo de ciudad compacta central, no se olvide) ha sido verdaderamente espectacular. En sintonía con lo señalado líneas atrás, el grueso de las 6.506 personas que entre 2004 y 2012 pasan a engrosar las listas

\footnotetext{
${ }^{10}$ Incluso los correspondientes a Encarnación, uno de estos barrios mejor individualizado por la estadística, están ocultos tras las altas residenciales habidas en las novedosas promociones de su entorno.
}

padronales lo hacen fundamentalmente en tres sectores urbanos, y, en esencia, en cada una de las seis secciones censales creadas a tal efecto ex novo (6.980 censados más). La búsqueda de espacios abiertos, de nuevas tipologías edificatorias o simplemente de inmuebles de calidad, en mayor cuantía y a precios más asequibles que en el «centro», son las razones que se suelen esgrimir a la hora de explicar la atracción de residentes hacia este tipo de áreas (que en el caso de Ávila, se vuelve a repetir, serían los dos grandes segmentos ubicados y expandidos hacia levante a norte y sur del espacio nuclear).

Dicotomía centro/periferia, como contraste evidente entre la ciudad tradicional (casco histórico más barrios) y la «moderna» ciudad ensanchada (la finisecular y la del boom inmobiliario), que se traduce de la misma manera en unas desiguales estructuras por edad, mucho más envejecidas (a la par que feminizadas) en el primero de estos ámbitos.

Así, se percibe un doble proceso de senectud, tanto por la cúspide como por la base de las pirámides de población, en la ciudad histórica, y muy especialmente en su sector de extramuros. Esto se debe a la escasa proporción de jóvenes $(12,93 \%$ y $11,44 \%$, en el recinto amurallado y el arrabal externo, respectivamente) y a la importancia relativa de los escalones correspondientes a la población anciana $(20,53 \%$ y $30,55 \%)$. Son, junto con el sector 6 (el segundo más sobreenvejecido, por cierto), dado el peso que dentro de él tienen los barrios más populares de La Cacharra, San Antonio y Estación, contrarrestado sólo en parte por Las Hervencias, las teselas urbanas que presentan, entre otros expresivos indicadores, las tasas e 


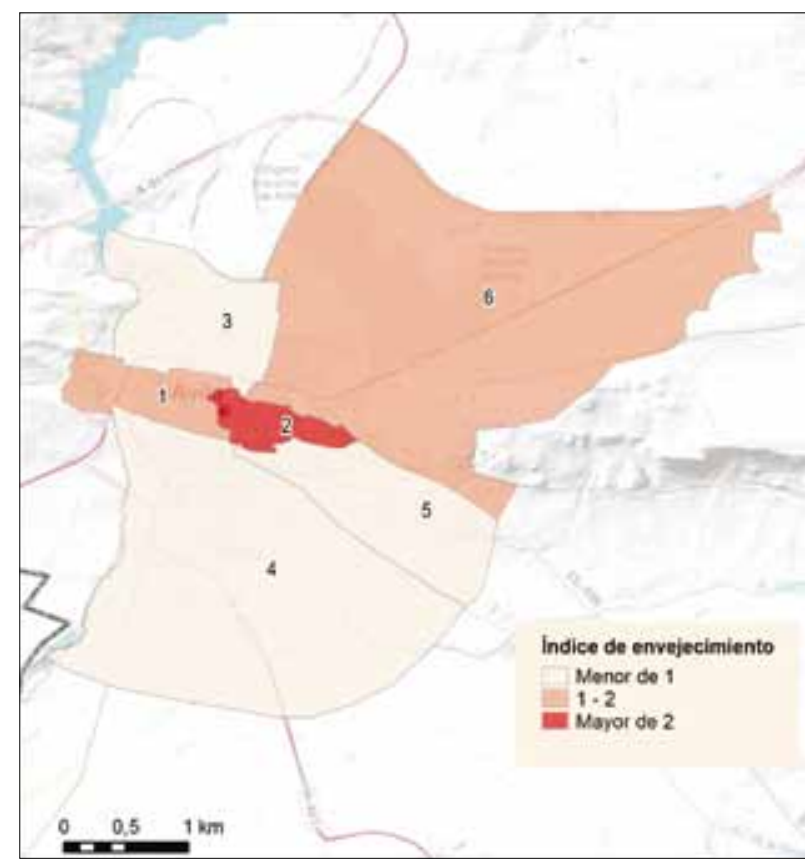

FIG. 10. Índice de envejecimiento por sectores urbanos en 2012. Fuente: elaboración propia a partir de Ayuntamiento de Ávila: Explotación estadística del Padrón municipal.

índices de vejez en valores por encima de las medias marcadas por el conjunto de la ciudad (16,95\% y 1,08\%).

Por el contrario, las unidades que capitalizan las progresiones inmobiliarias más contemporáneas (al margen de Las Hervencias) se confirman como los sectores donde la presencia de personas adultas (en edad activa, por consiguiente) y menores de 16 años es más elevada. En este sentido, es Encarnación, curiosamente, como gozne entre la «vieja» y la «nueva» ciudad, la pieza urbana que arroja los datos de un horizonte demográfico más alentador, presentando la relación de mayores y jóvenes (índice de envejecimiento) más contenida: 0,71. En una tónica parecida de marcadores «poco» envejecidos, los sectores 4 y 5 , los que se despliegan por toda la zona sur, en la charnela también entre los dos grandes dominios de la capital, logran equilibrar favorablemente las diferentes cohortes etarias; bien es cierto que mientras en el caso de San Nicolás-Las Vacas-La Toledana-Valle Amblés el reemplazo de población activa está asegurado (con un índice del 1,41, el más alto de toda la ciudad), en el de Santo Tomás-Universidad éste es más que cuestionable $(0,90)$, al no estar garantizado para el futuro próximo ese relevo generacional en la fuerza de trabajo, como consecuencia de la mayor presencia de población madura próxima a la edad jubilar (60-64 años) que de adultos-jóvenes de

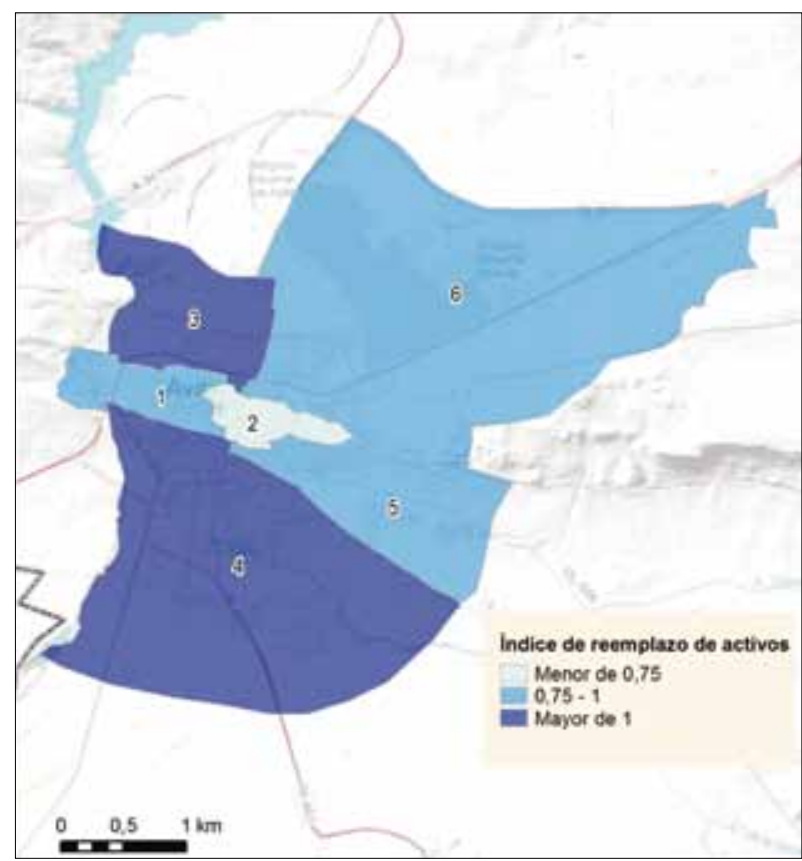

FIG. 11. Índice de reemplazo de activos por sectores urbanos en 2012. Fuente: elaboración propia a partir de Ayuntamiento de Ávila: Explotación estadística del Padrón municipal.

entre 15 y 19 años, los próximos en incorporarse potencialmente al mercado laboral.

\section{LAS VARIABLES DE LA DINÁMICA POBLACIONAL Y SU PROYECCIÓN. LOS DESAJUSTES CON EL MODELO DE CRECIMIENTO RESIDENCIAL PLANEADO}

A lo largo de más de sesenta años, la transformación espacial de Ávila se ha producido al compás que han marcado las dinámicas poblacionales. Del pequeño núcleo originario, en torno al casco medieval (intramuros y extramuros) se pasó, sin solución de continuidad, a una ciudad que se expandía, más allá de los límites históricos, por una serie de barrios que iban surgiendo al socaire del desarrollo migratorio procedente de la provincia y, sobremanera, del medio rural circundante (16.585 personas). La atracción urbana y el tímido apogeo de unas actividades que demandaban mano de obra propiciaron la temprana colmatación residencial (décadas de 1950 a 1970) de las zonas adosadas al «centro» de la capital (2.737 edificios destinados a vivienda fueron construidos en esa época). Desde los años ochenta, la potenciación de las bases económicas a partir del estímulo del turismo, las mejoras de la función administrativa y comercial y 


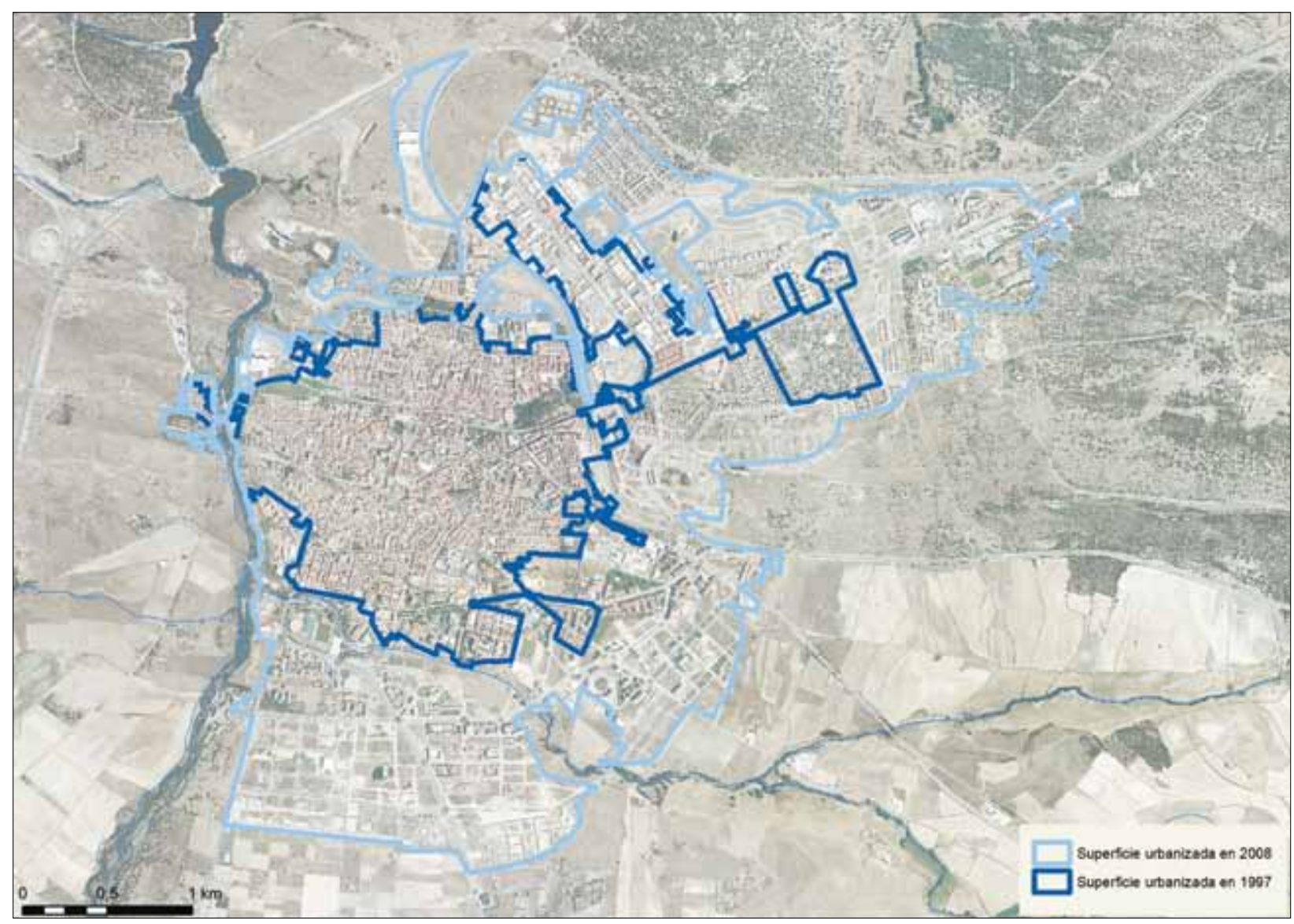

FIG. 12. Evolución reciente de la superficie urbanizada de la ciudad de Ávila, 1997-2008. Fuente: elaboración propia.

el impulso de la producción industrial, unidas al hecho natural de la emancipación y reproducción de parte de la abundante población en edades y situación de hacerlo (generaciones del baby boom de los sesenta y primeros setenta), y a pesar de las regresiones habidas en los saldos vegetativos durante los noventa, contribuyeron como factores de consuno a la expansión (7.794 habitantes y 1.964 edificios levantados) de la Ávila finisecular.

Una ampliación de la ciudad que no ha conocido límites durante la primera década del siglo xxi: 11.041 habitantes y 2.284 nuevas edificaciones, en un ensanchamiento del perímetro urbanizado sin precedentes, dadas las bajas densidades medias de ocupación habitacional de las modernas promociones de vivienda. La movilidad residencial hacia la periferia, que en el caso que nos ocupa no hace sino reforzar el modelo de ciudad compacta, sin los efectos de difusión conocidos en las áreas urbanas del presente, no es óbice para que Ávila manifieste las contradicciones del crecimiento residencial efectuado (siguiendo, además, esa estrategia decidida de abandono de los espacios tradicionales). Así son los trazos actuales de la «ciudad del boom inmobiliario», la que, por encima de las necesidades reales (demanda efectiva), que vienen marcadas por las pulsaciones poblacionales, se dimensiona desorbitadamente en función de una conjunción de intereses urbanísticos totalmente lastrados, a la postre, por la crisis que vivimos (Serrano, 2004 y 2010).

Nunca antes en la historia de la ciudad se han construido tantas viviendas, ni tantas de ellas permanecen vacías (y sin vender, como lo atestigua el balance de transacciones inmobiliarias del Ministerio de Fomento). $\mathrm{Al}$ significativo número de las alojadas en el casco y en los bloques levantados en los barrios más populares (en esa suerte de trasvase residencial intraurbano), el último decenio concluido arroja resultados verdaderamente elocuentes: el $46 \%$ de la producción inmobiliaria de esos años se encuentra desocupado. Y ello en una década, bien es cierto, de importancia en lo que a afianzamiento del vecindario se refiere. Un periodo en el que cobran fuerza tanto las ganancias por movimientos migratorios como 
CUADRo IX. Número de viviendas en Ávila por etapa de construcción y tipo de uso actual

\begin{tabular}{|c|c|c|c|c|c|c|c|c|}
\hline & Antes de 1950 & Años 50 & Años 60 & Años 70 & Años 80 & Años 90 & Años 2000 & Total ciudad \\
\hline Principales & 2.999 & 2.082 & 2.314 & 4.827 & 3.169 & 3.075 & 4.304 & 22.770 \\
\hline Secundarias & 347 & 485 & 411 & 594 & 288 & 394 & 987 & 3.506 \\
\hline Vacías & 510 & 912 & 698 & 1.212 & 369 & 425 & 4.063 & 8.189 \\
\hline TотAL & 3.856 & 3.479 & 3.423 & 6.633 & 3.826 & 3.894 & 9.354 & 34.465 \\
\hline
\end{tabular}

Fuente: INE: Censo de población y viviendas.

CUADRo X. Movimientos migratorios en Ávila capital, 2005 a 2011

\begin{tabular}{|c|c|c|c|c|c|c|}
\hline \multirow[b]{2}{*}{ Año } & \multicolumn{3}{|c|}{ Migraciones interiores (dentro de España) } & \multicolumn{3}{|c|}{ Migraciones exteriores (internacionales) } \\
\hline & Saldo & Inmigraciones & Emigraciones & Saldo & Inmigraciones & Emigraciones \\
\hline 2005 & 486 & 1.675 & 1.189 & 775 & 786 & 11 \\
\hline 2006 & 354 & 1.913 & 1.559 & 1.044 & 1.062 & 18 \\
\hline 2007 & 435 & 2.187 & 1.752 & 1.565 & 1.633 & 68 \\
\hline 2008 & -24 & 1.526 & 1.550 & 770 & 842 & 72 \\
\hline 2009 & 129 & 1.718 & 1.589 & 424 & 628 & 204 \\
\hline 2010 & -187 & 1.562 & 1.749 & 391 & 484 & 93 \\
\hline 2011 & -171 & 1.592 & 1.763 & 324 & 375 & 51 \\
\hline
\end{tabular}

Fuente: INE: Estadística de variaciones residenciales.

por la propia dinámica positiva del crecimiento vegetativo de la población. Los unos engrosados, aunque no exclusivamente, por los importantes flujos de inmigrantes extranjeros llegados a la capital, tan relevantes en el sostén de la actividad económica y la renovación de las estructuras demográficas (3.827 entre 2004 y 2012); en franca y progresiva ralentización desde 2008, pero que han proseguido paliando numéricamente a los abulenses (autóctonos o previamente ya empadronados) que se marchan. Y unos saldos naturales, recuperados desde 2003, favorables siempre a tenor de las más altas tasas de natalidad que de mortalidad registradas, gracias a una evolución de la fecundidad (número de hijos por mujer) relativamente elevada: 1,47 para 2011 (por 1,26 en el caso de la provincia, 1,18 en el de la comunidad y 1,36 en el conjunto de España).

La Ávila contemporánea se fragua al calor de las disposiciones contempladas en el Plan General de Ordenación Urbana de 1998, prolongado en su fundamentación de asociar una alta disponibilidad de suelo urbanizable a la mejora de la capacidad de acceso a la vivienda por la adaptación-revisión de 2005, que es el instrumento de planeamiento vigente a día de hoy. Entre 1998 y 2004 se desarrollan 22 de los 40 planes parciales previstos, construyéndose 11.253 viviendas, la mitad de las proyectadas, pero mucho más de las necesarias, ya que en ese lapso de tiempo la ciudad se incrementó en 4.676 habitantes (Calderón, 2012 y 2013). En 2005 se delimitarían otros 18 nuevos sectores de suelo urbanizable (y uno aparte en Vicolozano como ampliación del polígono industrial), con capacidad, nada más y nada menos, para 11.560 viviendas (manteniéndose a su vez el propósito de edificar las 10.500 que quedaban pendientes), esgrimiéndose la máxima de no introducir incertidumbre entre unos agentes (promotores, constructores y financiadores) activos e implicados en plena vorágine de optimismo urbanizador.

Tras el estallido de la «burbuja» inmobiliaria, la ciudad prepara su futuro de la mano de una nueva herramienta planificadora (en estado de «avance») que estima una población horizonte en 2030 de 100.000 habitantes (recogiendo la idea del Plan 100.000 esbozada por el Plan Estratégico de Desarrollo Industrial de la Ciudad de Ávila, lanzado en 2006) y hasta 11.000 nuevas viviendas (además de un nuevo espacio industrial junto a la autovía a Salamanca, otro hospital, un tercer centro comercial, el recinto ferial, entre otras actuaciones de calado), que se 
CUADRo XI. Movimiento natural de la población en Ávila capital, 2005 a 2011

\begin{tabular}{|c|c|c|c|c|c|c|}
\hline \multirow[b]{2}{*}{ Año } & \multicolumn{2}{|c|}{ Natalidad } & \multicolumn{2}{|c|}{ Mortalidad } & \multicolumn{2}{|c|}{ Crecimiento vegetativo } \\
\hline & Número & Tasa $(\%)$ & Número & Tasa $(\% o)$ & Número & Tasa $(\% o)$ \\
\hline 2005 & 568 & 10,73 & 468 & 8,84 & 100 & 1,89 \\
\hline 2006 & 600 & 11,21 & 465 & 8,69 & 135 & 2,52 \\
\hline 2007 & 637 & 11,51 & 476 & 8,66 & 161 & 2,93 \\
\hline 2008 & 689 & 12,19 & 483 & 8,55 & 206 & 3,65 \\
\hline 2009 & 691 & 12,01 & 514 & 8,93 & 177 & 3,08 \\
\hline 2010 & 634 & 10,81 & 465 & 7,93 & 169 & 2,88 \\
\hline 2011 & 625 & 10,60 & 456 & 7,73 & 169 & 2,87 \\
\hline
\end{tabular}

Fuente: INE: Movimiento natural de la población y SIE (almacén de datos multidimensional de la Junta de Castilla y León).

CUADRO XII. Ávila: previsiones y grado de ejecución del PGOU de 1998

\begin{tabular}{|c|c|c|c|c|}
\hline Usos del suelo & \multicolumn{2}{|c|}{ Previsiones PGOU 1998} & Desarrollado (en 2004) & Pendiente \\
\hline \multirow{2}{*}{ Suelo Urbano No Consolidado } & Superficie $\left(\mathrm{m}^{2}\right)$ & 1.344 .142 & 666.990 & 471.938 \\
\hline & N.o máximo de viviendas & 2.300 & 719 & 1.060 \\
\hline \multirow{2}{*}{ Suelo Urbanizable Delimitado } & Superficie $\left(\mathrm{m}^{2}\right)$ & 5.553 .531 & 2.319 .224 & 2.780 .141 \\
\hline & N. ${ }^{o}$ máximo de viviendas & 20.513 & 10.013 & 10.500 \\
\hline
\end{tabular}

Fuente: Calderón (2012, p. 799).

añadirían a las 8.189 desocupadas según censo del 2011. Una visión harto generosa, a nuestro juicio, por cuanto la progresión demográfica da señales de agotamiento y de un cambio de tendencia que en el mejor de los escenarios proyectados situaría el contingente poblacional de la capital, para 2027, en 60.325 habitantes, bajando en la hipótesis más factible a los $54.390^{11}$.

\section{LA CIUDAD Y SU ESPECIALIZACIÓN FUNCIONAL COMO CENTRO DE ADMINISTRACIÓN Y PRESTACIÓN DE SERVICIOS}

\section{LOS LÍMITES DE UNA ECONOMÍA TERCIARIA}

Ávila es, primero y antes de cualquier otra conceptualización, un centro administrativo (Fernández y otros, 1989). Es capital de provincia, con todo lo que esa cir-

\footnotetext{
${ }^{11}$ Según las estimaciones realizadas por José María Delgado Urrecho, profesor del Departamento de Geografía de la Universidad de Valladolid, y que nos han sido facilitadas para la elaboración de este estudio.
}

cunstancia ha supuesto para el desarrollo moderno de los enclaves urbanos del país (Delgado, 1993). Y se erige, como fue constatado al comienzo, en núcleo de referencia para la provisión de servicios a una parte de la población provincial. Un centro administrativo lastrado de tradición, así ha sido enfatizado en alguna ocasión, ya que son los servicios derivados de su condición capitalina y la tradición comercial los fundamentos sobre los que descansa, aún, el grueso de la actividad (Villar, 1999). Es la pervivencia de un legado histórico en lo que al funcionamiento de las relaciones económicas y de la trabazón de la ciudad con su entorno se refiere. La herencia de una ciudad histórica que, sin talla productiva de entidad, encuentra en esa misma tradición y en la riqueza patrimonial la manera de afianzar (por la vía del turismo) su especialización (Troitiño, 1998).

Una manifiesta especialización en las actividades terciarias (el 87,3\% del empleo), superior a la ya de por sí importante de la provincia y de Castilla y León en su conjunto, que dentro de las áreas urbanas de ésta sólo es superada por Salamanca. En una cuantía nada desdeñable (23.055 trabajadores y 2.284 empresas, $87,9 \%$ de las radicadas en el municipio) el variopinto muestrario de ocupaciones terciarias, tan difíciles de tipificar y clasifi- 
CuADro XIII. Estructura del empleo en las áreas urbanas de Castilla y León, en Ávila y su provincia, 2010

\begin{tabular}{|c|c|c|c|c|c|}
\hline \multirow[b]{2}{*}{ Área urbana } & \multicolumn{5}{|c|}{$\%$ de empleo sobre el total } \\
\hline & Agrario & Industria & Const. & Servicios & TOTAL \\
\hline Ávila & 1,3 & 7,4 & 4,0 & 87,3 & 100 \\
\hline Aranda de Duero & 4,7 & 33,1 & 3,2 & 59,1 & 100 \\
\hline Miranda de Ebro & 1,9 & 25,3 & 4,2 & 68,5 & 100 \\
\hline Ponferrada & 0,9 & 13,6 & 4,9 & 80,6 & 100 \\
\hline Burgos & 1,0 & 20,4 & 3,5 & 75,0 & 100 \\
\hline León & 1,1 & 9,1 & 2,7 & 87,1 & 100 \\
\hline Palencia & 1,6 & 20,5 & 2,8 & 75,1 & 100 \\
\hline Salamanca & 1,2 & 6,9 & 3,2 & 88,7 & 100 \\
\hline Segovia & 1,7 & 8,4 & 4,5 & 85,5 & 100 \\
\hline Soria & 2,1 & 13,1 & 3,8 & 81,0 & 100 \\
\hline Valladolid & 1,7 & 13,6 & 2,8 & 81,9 & 100 \\
\hline Zamora & 2,7 & 6,6 & 4,2 & 86,4 & 100 \\
\hline TOTAL áreas urbanas & 1,5 & 13,4 & 3,3 & 81,8 & 100 \\
\hline Provincia de Ávila & 9,8 & 10,1 & 7,5 & 72,6 & 100 \\
\hline Castilla y León & 7,3 & 15,6 & 4,3 & 72,8 & 100 \\
\hline
\end{tabular}

Fuente: elaboración propia a partir de Ministerio de Trabajo y Seguridad Social: Explotación estadística de datos de afiliación de trabajadores al sistema de la Seguridad Social por régimen, municipio y actividad (CNAE-09), diciembre de 2010.

car, puede ser sintetizado, haciendo un ejercicio de abstracción no exento de simplismo, en los tres grandes ámbitos de especialidad funcional abulense: administración y servicios básicos (no todo, pero sí en buena medida, lo que en términos académicos se identifica con el terciario público), el comercio y las actividades ligadas directa o indirectamente al turismo. En total el 71,8 \% de todo el empleo en el sector, incluyendo al importante ramo bancario (en proceso de reestructuración); y dejando fuera de la consideración actividades igualmente relevantes como las profesiones liberales, los servicios a las empresas, el transporte y almacenamiento, entre otras, empero que no hacen sino reforzar el cariz dominante de la economía local.

La administración pública, es decir, los empleados de las instituciones y organismos dependientes del Estado (Subdelegación del Gobierno y delegaciones provinciales correspondientes - Hacienda, Seguridad Social...-, cuerpos y fuerzas de seguridad, administración de justicia), de la comunidad autónoma (Delegación Territorial de la Junta de Castilla y León, y servicios de las distintos entes y consejerías adscritas a ésta), Diputación Provincial y Ayuntamiento, representaban, en suma, el 9,8\% de todos los ocupados en el municipio de Ávila en 2010. A ellos habrían de añadirse los trabajadores pertenecientes a otras instituciones, algunas privadas, pero mayoritaria- mente sufragadas por el erario público, englobadas en lo que de manera laxa pudieran ser los servicios básicos de sanidad, educación y servicios sociales. Los primeros son los más numerosos. De este modo, 3.088 trabajadores se vinculan al sector sanitario de la capital; en ella se concentran, por este hecho, los equipamientos hospitalarios fundamentales del área de salud (que coincide con el espacio provincial) ${ }^{12}$, así como los cinco centros de salud y siete consultorios de las doce zonas básicas de salud, que articulan la atención primaria a la población residente en la ciudad y su zona de influencia más inmediata.

Los trabajadores de la enseñanza (profesores y personal de administración y servicios) representan a otras 1.965 personas empleadas, contando la ciudad con 37 centros que imparten docencia en los diferentes ciclos y niveles de enseñanza no universitaria (16 colegios públicos de infantil y primaria, cinco institutos de secundaria y bachillerato y ocho centros concertados y privados), edu-

\footnotetext{
${ }^{12}$ En la cúspide del sistema sanitario provincial se encuentra el Complejo Asistencial de Ávila, compuesto por cuatro centros: el Hospital Nuestra Señora de Sonsoles, el Hospital Provincial, el Centro de Especialidades de Ávila y el Centro de Especialidades de Arenas de San Pedro. Este último, sin ser verdaderamente un hospital comarcal, centraliza los servicios médicos más especializados en el menos accesible borde meridional de la provincia, evidenciándose, una vez más, las limitaciones de la capital para vertebrar parte del territorio que administra.
} 


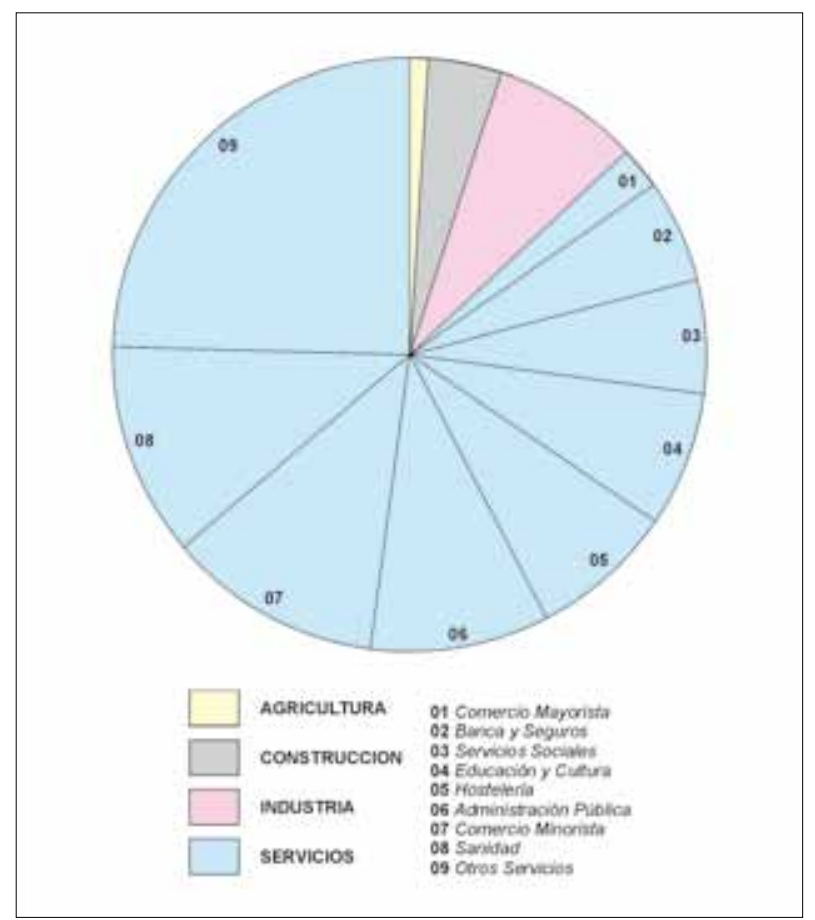

FIG. 13. Estructura del empleo en el municipio de Ávila en 2010. Fuente: elaboración propia a partir de Ministerio de Trabajo y Seguridad Social: Explotación estadística de datos de afiliación de trabajadores al sistema de la Seguridad Social por régimen, municipio y actividad (CNAE09), diciembre de 2010.

cación especial (dos concertados), educación de adultos, conservatorio, escuela de música, capacitación agraria, escuela de arte y centro de idiomas. Un sistema educativo que refuerza, de algún modo, el rango capitalino de la ciudad en la prestación de los servicios de más alto nivel al constituirse Ávila como ciudad universitaria. Es, en efecto, campus de la Universidad de Salamanca ${ }^{13}$, contando, a la vez, con un centro adscrito de la Universidad Nacional de Educación a Distancia y con su propia universidad privada, la Universidad Católica de Ávila ${ }^{14}$.

${ }^{13}$ La Universidad de Salamanca (Usal) cuenta con cuatro campus universitarios: Salamanca, Zamora, Ávila y Béjar. En el abulense se integran la Escuela Politécnica Superior de Ávila (estudios de ingeniería civil, ingeniería geomática y topografía e ingeniería de la tecnología de minas y energía) y la Escuela Universitaria de Educación y Turismo, además de contar con un centro adscrito como es la Escuela Universitaria de Enfermería.

${ }^{14}$ La Universidad Católica de Ávila (Ucav) se crea en 1997. En la actualidad imparte en sus dos facultades enseñanzas sociales y jurídicas (derecho, economía, administración y dirección de empresas, educación infantil y primaria), ingenierías (forestal, agropecuaria, mecánica, sistemas de información), ciencias ambientales, enfermería y fisioterapia. Así como otra serie de títulos propios y posgrados en esas materias. A título anecdótico, se hace mención de la existencia de la Universidad de la Mística-cites, fundada en 1986 por los carmelitas descal-
Finalmente, 1.644 trabajadores abulenses se dedican a la atención social. 914 de ellos lo hacen bien por cuenta propia bien como empleados en los cuatro centros de acción social distribuidos por la ciudad, así como en los nueve centros de día y hogares del pensionista. Mientras que otros 730 lo hacen atendiendo en los diferentes establecimientos residenciales de la capital (ocho, entre residencias públicas y privadas).

El comercio es un sector económico clave para la ciudad $^{15}$. Ha sido, de siempre, la gran alternativa laboral a la excesiva dependencia del «sector público» y de la administración en general. Mayoristas y, esencialmente, comerciantes y empleados del comercio al por menor vienen a ser catorce de cada cien abulenses que trabajan. Se trata primordialmente de un comercio tradicional, por la herencia histórica de la capital como núcleo comercial y por su grado de especialización y de tenue renovación. La alimentación es el subsector con mayor representatividad y distribución espacial. Tenderos a pie de calle, en paulatina desaparición, contrastan ante la competencia de los modernos comercios de proximidad: supermercados y autoservicios, en expansión al socaire de las nuevas demandas y hábitos de compra. Más polarizado en su localización, el comercio de productos no alimenticios trasciende la esfera de barrio e incluso la local para desbordar con su capacidad de atracción al ámbito comarcal, si bien solamente hace gravitar torno a sí a una parte representativa del provincial, la más accesible a la capital (recuérdese la cartografía de los espacios comerciales de la provincia representada a tal efecto).

Tres son las ubicaciones urbanas preferentes del comercio más especializado. La derivada de la histórica función del «centro» como lugar comercial por antonomasia (calles Duque de Alba y Marquina), con un corolario de zapaterías, boutiques de ropa y tiendas de complementos de todo tipo, que se debate, actualmente, entre el cierre paulatino de establecimientos, la recualificación decidida de los que persisten (organizados en Centro Comercial Abierto) y la lábil inserción de franquicias. Aquella elegida por las actividades comerciales que necesitan con-

\footnotetext{
zos, que imparte, aprovechando la invocación cultural de santa Teresa y san Juan de la Cruz, másteres en mística y espiritualidad de reconocimiento internacional.

${ }^{15}$ Como lo constata el hecho de que se haya vinculado a todo el sector con una imagen de marca propia: ComerciodeÁvila. Su objetivo es dinamizar y consolidar uno de los sectores más arraigados en la capital, a instancias de la Mesa del Comercio liderada por el Ayuntamiento y de la que son miembros la Junta de Castilla y León, la Cámara de Comercio e Industria de Ávila, la Confederación Abulense de Empresarios, UGt, CCoo, así como la Federación Abulense de Empresarios de Comercio, la Asociación de Comerciantes de la Zona Norte y el Centro Comercial Abierto Ávila Centro.
} 
CuADro XIV. Comercio y tipos de comercio en Ávila capital, 2010-2011

\begin{tabular}{|c|c|c|c|}
\hline Establecimientos comerciales & 2010 & 2011 & Variación (\%) \\
\hline TOTAL & 1.572 & 1.528 & $-2,8$ \\
\hline Comercio al por mayor e intermediarios & 253 & 252 & $-0,4$ \\
\hline Comercio al por menor & 1.319 & 1.276 & $-3,3$ \\
\hline Comercio al por menor de alimentación, bebidas y tabaco & 306 & 301 & $-1,6$ \\
\hline Frutas, verduras, hortalizas y tubérculos & 25 & 26 & 4,0 \\
\hline Carnes, despojos, huevos, aves, conejo, caza & 60 & 60 & 0,0 \\
\hline Pescados y otros productos de la pesca & 13 & 12 & $-7,7$ \\
\hline Pan, pastelería, confitería y productos lácteos & 62 & 57 & $-8,1$ \\
\hline Vinos y bebidas de todas clases & 0 & 0 & 0,0 \\
\hline Labores de tabaco y productos de fumador & 48 & 49 & 2,1 \\
\hline Productos alimenticios y bebidas en general & 98 & 97 & $-1,0$ \\
\hline Comercio al por menor de productos no alimenticios & 930 & 891 & $-4,2$ \\
\hline Textil, confección, calzado y artículos de cuero & 262 & 246 & $-6,1$ \\
\hline Productos farmacéuticos, droguería, perfumería y cosmética & 85 & 84 & $-1,2$ \\
\hline Equipamiento hogar, bricolaje, constr. y saneamiento & 231 & 214 & $-7,4$ \\
\hline Vehículos, accesorios y recambios & 118 & 110 & $-6,8$ \\
\hline Combustibles, carburantes y lubricantes & 15 & 19 & 26,7 \\
\hline Bienes usados (muebles y enseres de uso doméstico) & 0 & 0 & 0,0 \\
\hline Instrumentos musicales y accesorios & 2 & 2 & $-0,0$ \\
\hline Otro comercio al por menor & 217 & 216 & $-0,5$ \\
\hline Comercio al por menor mixto y otros & 83 & 84 & 1,2 \\
\hline Grandes almacenes & 0 & 0 & 0,0 \\
\hline Hipermercados & 2 & 2 & 0,0 \\
\hline Almacenes populares & 2 & 2 & 0,0 \\
\hline Resto & 79 & 80 & 1,3 \\
\hline
\end{tabular}

Fuente: Caja España: Datos económicos y sociales de las unidades territoriales de España 2012.

sumir más espacio (vehículos, accesorios, equipamientos varios y sector comercial mixto de apoyo a otros sectores económicos) con especial predilección por los polígonos industriales y carreteras de salida de la ciudad. Y la más novedosa en cuanto a implicación e importación de fórmulas y estrategias comerciales (y de planificación urbanística, por qué no decirlo) de las grandes superficies comerciales. Éstas se han dimensionado en función de los incrementos poblacionales y de los cambios en las pautas de consumo habidos a lo largo de los últimos decenios, implantándose en los dos ejes de crecimiento residencial principal de la ciudad: al sur, el más temprano, fue el asiento elegido por el modesto HiperSimply (del grupo Auchan), que cuenta con una pequeña galería comercial, hoy prácticamente desocupada; y tomando como referencia al sector noreste, el centro comercial El Bulevar, inaugurado en 2001, con 65 locales comerciales, área de ocio y restauración e hipermercado asociado (Carrefour), termina por introducir en la zona de Las Hervencias una nueva «centralidad» urbana y comercial, hacia la que se ha trasladado parte de las firmas comerciales de moda y más aceptación de la ciudad y su radio de influjo.

Administración, prestación de servicios capitalinos y funciones comerciales otorgan carta de entidad a la economía local. Una economía de base terciaria común a la de otras muchas pequeñas capitales de provincia del país. Pero si algo define también a la ciudad es su riqueza patrimonial. La ciudad, a la que Azorín denominara «paradigma del siglo XVI», ha fundado parte de su desarrollo más reciente en la explotación de los valores culturales (y paisajísticos) que atesora a través de una cierta actividad turística más o menos diversificada (Troitiño y Troitiño, 2009). El significado primordial de las murallas, la iglesia catedral de San Salvador, los lugares teresianos, el 
CuAdro XV. Evolución de la demanda turística en Ávila capital, 1999 a 2012

\begin{tabular}{|c|c|c|c|c|c|c|c|}
\hline & \multicolumn{3}{|c|}{ Número de viajeros } & \multicolumn{4}{|c|}{ Número de pernoctaciones } \\
\hline & TOTAL & Españoles & Extranjeros & TOTAL & Españoles & Extranjeros & Estancia media \\
\hline 1999 & 170.228 & 134.655 & 35.573 & 245.087 & 197.760 & 47.327 & 1,44 \\
\hline 2000 & 167.520 & 134.135 & 33.385 & 251.586 & 204.417 & 47.169 & 1,50 \\
\hline 2001 & 201.294 & 167.307 & 33.987 & 300.356 & 255.387 & 44.969 & 1,49 \\
\hline 2002 & 201.930 & 168.181 & 33.749 & 295.185 & 250.233 & 44.952 & 1,46 \\
\hline 2003 & 195.057 & 165.590 & 29.467 & 289.484 & 249.675 & 39.809 & 1,48 \\
\hline 2004 & 222.140 & 194.801 & 27.338 & 331.251 & 288.753 & 42.499 & 1,49 \\
\hline 2005 & 225.627 & 196.160 & 29.467 & 349.341 & 300.968 & 48.373 & 1,55 \\
\hline 2006 & 226.457 & 196.375 & 30.082 & 360.991 & 312.479 & 48.512 & 1,59 \\
\hline 2007 & 235.468 & 198.395 & 37.073 & 376.031 & 320.845 & 55.186 & 1,60 \\
\hline 2008 & 217.363 & 181.379 & 35.984 & 354.540 & 298.351 & 56.189 & 1,63 \\
\hline 2009 & 197.970 & 166.886 & 28.084 & 320.307 & 277.581 & 42.726 & 1,62 \\
\hline 2010 & 203.625 & 165.054 & 38.571 & 340.078 & 275.671 & 64.407 & 1,67 \\
\hline 2011 & 203.231 & 163.014 & 40.217 & 335.541 & 265.976 & 69.565 & 1,65 \\
\hline 2012 & 185.320 & 151.975 & 33.345 & 302.794 & 251.635 & 51.159 & 1,63 \\
\hline
\end{tabular}

Fuente: Ayuntamiento de Ávila: Observatorio Turístico de la Ciudad de Ávila.

valor de las iglesias románicas y monasterios de extramuros, las casas y palacios nobiliarios, las calles y plazas de urdimbre medieval han hecho merecer la inclusión de Ávila, desde 1985, en la lista de ciudades patrimonio de la humanidad. Ello ha servido de acicate a la demanda de turistas que la visitan y como punto de partida inicial para una oferta cada vez más amplia, de mayor calidad y diversificación ${ }^{16}$ (Hortelano, 2010), siguiendo las directrices enunciadas por el Plan de Excelencia Turística, puesto en marcha en el año 2000, y en la Estrategia de Turismo 2015. Un número de turistas y de visitantes (los que no pernoctan) en considerables cifras y tendencias positivas a lo largo de los primeros dos mil (a sabiendas de que el turismo manifiesta, más rápidamente que ningún otro sector, los vaivenes de la situación económica general).

Como consecuencia de estos flujos, y al margen de los ocupados directamente por el sector (guías, personal de museos, oficinas de turismo, centros de recepción, interpretación) y del revulsivo de beneficios que supo-

\footnotetext{
${ }^{16}$ Apostando, por ejemplo, por la potenciación del turismo de reuniones y congresos, ya que es bien sabido que este tipo de eventos genera un gasto medio por persona del orden de cinco a siete veces superior al del turismo convencional (cultural y de interior), además de contribuir decididamente al fortalecimiento y difusión de la imagen de ciudad. Emblemático, en este sentido, y como magnífico escenario para acoger este tipo de acontecimientos, es el Centro de Congresos y Exposiciones Lienzo Norte, inaugurado en 2010.
}

nen para la actividad comercial, unas 2.094 personas se puede decir pertenecen al elenco de oficios de hostelería, restauración y hospedaje; 41 hoteles y hostales que hablan directamente de la pujanza de un sector que contribuye decisivamente, por lo demás, al mantenimiento de los restaurantes, cafeterías y locales al servicio del ocio en la ciudad.

\section{LA ATONÍA DE LAS ACTIVIDADES PRODUCTIVAS}

Según el Observatorio de Empleo municipal, Ávila es la capital de provincia castellana y leonesa con la tasa de paro situada en niveles más altos (más del $20 \%$ ). Con una tasa de activos dos puntos por encima de la media de las capitales de la comunidad $(67,29 \%$ por $65,16 \%)$, se pierden anualmente en la ciudad 3.500 contratos. La situación del mercado de trabajo refleja, en parigual, la práctica saturación de las actividades de servicios en lo que a capacidad de creación de empleo se refiere. Son los límites de la terciarización que ha fundamentado el devenir económico de la ciudad. Sin las posibilidades de ocupación en el mermado sector público, con las fluctuaciones turísticas y del mercado de ocio local amenazando a un buen número de trabajadores que de ello dependen y con un descenso sin freno del número de comercios (más de un centenar clausurados en 2011) el horizonte laboral se presenta poco halagüeño. 
CuAdro XVI. Oferta de alojamiento turístico en Ávila capital, 2012

\begin{tabular}{|c|c|c|}
\hline & Número de plazas & Número de establecimientos hoteleros \\
\hline Hoteles de cuatro estrellas & 952 & 6 \\
\hline Hoteles de tres estrellas & 931 & 10 \\
\hline Hoteles de una y dos estrellas & 352 & 8 \\
\hline Hostales y pensiones & 461 & 17 \\
\hline TOTAL & 2.696 & 41 \\
\hline
\end{tabular}

Fuente: Ayuntamiento de Ávila: Observatorio Turístico de la Ciudad de Ávila.

La mirada se torna, pues, al resto de actividades productivas (construcción e industria) que acaban por completar la estructuración económica y ocupacional abulense. La construcción venía a representar en 2010 el $4 \%$ de dicho reparto. Se palpaba entonces ya el signo inequívoco de una crisis que por su especial naturalidad se ha continuado cebando con el que justo en la etapa de bonanza anterior (y a la par de la expansión urbanística sin precedentes de la ciudad) era el sector refugio demandante de ocupación.

No es Ávila ni mucho menos una ciudad industrial. Es el undécimo enclave en el ranking de áreas urbanas y centros industriales de la región (Pascual, 2012). Solamente Zamora presenta cifras todavía menores, y junto con Segovia y Soria caracterizan al grupo de núcleos capitalinos donde la producción y el empleo manufacturero apenas tienen relevancia. 1.965 trabajadores, el $7,4 \%$ del total, y 118 empresas vinculadas al sector. El tejido productivo es también el común a todos ellos, y se basa en la presencia de pequeñas empresas suministradoras de productos de alimentación, de metales ligeros, artes gráficas, materiales de construcción, derivados de la madera, muebles, cuero y confección, distribución y suministro de agua y energía, fabricación y reparación de maquinaria y equipo, etc., sobre las que destacan algunas implantaciones industriales de mayor entidad y ajenas al capital local, como la factoría de automoción de vehículos industriales de Nissan, la alimentaria Luxtor o las relacionadas con la experimentación y seguridad vial (Cesvimap) o el tratamiento de automóviles fuera de uso del grupo Mapfre.

Los polígonos industriales se convierten en los espacios de mayor interés para la ubicación de la industria (y de parte del sector comercial, como se apuntó). Dos son los existentes en el municipio de Ávila. El más antiguo de Las Hervencias (cuya primera fase data de 1975), en el margen nororiental de la ciudad, bien localizado en torno a las carreteras N-110 a Villacastín y N-403 a Adanero-
Valladolid, próximo al ferrocarril y a la planta de fabricación de Fadisa (antecedente de Nissan Motor Ibérica); ubicándose en él también el parque empresarial Cordel de las Moruchas. Y el más moderno, desde finales de los años noventa, de Vicolozano, radicado en la localidad homónima, a cinco kilómetros de la capital. Sobre ellos ha de cimentar Ávila las posibilidades de implementación de su potencial económico-industrial y logístico. De esta manera, el polígono industrial de Vicolozano ha pasado a formar parte de la red de espacios de innovación de la comunidad. Así aparece contemplado en la Estrategia Regional de Investigación Científica, Desarrollo Tecnológico e Innovación de Castilla y León, que persigue dispersar la actual concentración de actividad innovadora regional y aumentar el número de empresas de alta y media tecnología. Al tiempo, la ciudad se ha erigido en enclave logístico. El Centro Logístico de Ávila (Celoga), situado parejo al polígono de Las Hervencias y con reserva de suelo para su ampliación, puede hacer valer, finalmente, por su virtualidad como plataforma intermodal y puerto seco, el idóneo posicionamiento geoestratégico de la ciudad en el haz de comunicaciones ferroviarias de mercancías de Madrid con el norte del país y en las cercanías del eje dinámico de la A-6.

\section{CONCLUSIONES}

La ciudad de Ávila viene a ocupar el noveno lugar, por número de habitantes, en la clasificación del sistema urbano de Castilla y León. Sus 59.008 habitantes dan las pautas para su definición como una ciudad de tamaño intermedio en el contexto de la comunidad. Es capital de provincia, si bien en su proceso de desarrollo moderno, carente de un impulso de acumulación social y productiva de más intensidad, no ha logrado articular a la totalidad del territorio que administra. $\mathrm{Y}$ aparece incorporada, además, a radios de relaciones espaciales más amplios, 
CuADro XVII. Estructura empresarial y de empleo en la industria asentada en el municipio de Ávila, 2010

\begin{tabular}{|c|c|c|}
\hline Subsectores industriales & Número de empresas & Número de trabajadores \\
\hline Alimentación & 29 & 604 \\
\hline Fabricación de vehículos & 2 & 523 \\
\hline Recogida, tratamiento y eliminación de residuos & 9 & 207 \\
\hline Artes gráficas y reprod. de soportes grabados & 13 & 98 \\
\hline Captación, depuración y distribución de agua & 2 & 74 \\
\hline Suminist. de electricidad, gas, aire acondicionado & 5 & 72 \\
\hline Fabricación de productos metálicos & 17 & 70 \\
\hline Fabricación de otros productos minerales & 8 & 47 \\
\hline Fabricación de maquinaria y equipo & 7 & 47 \\
\hline Fabricación de productos de caucho y plásticos & 5 & 43 \\
\hline Industria de la madera y del corcho & 5 & 39 \\
\hline Fabricación de otro material de transporte & 1 & 36 \\
\hline Confección de prendas de vestir & 3 & 21 \\
\hline Fabricación de muebles & 3 & 19 \\
\hline Reparación e instalación de maquinaria y equipo & 2 & 13 \\
\hline Industria textil & 1 & 12 \\
\hline Fabricación de bebidas & 2 & 12 \\
\hline Metalurgia & 0 & 9 \\
\hline Otras industrias manufactureras & 2 & 8 \\
\hline Industria química & 1 & 4 \\
\hline Otras industrias extractivas & 0 & 3 \\
\hline Industria del cuero y del calzado & 0 & 1 \\
\hline Fabricación de productos farmacéuticos & 1 & 1 \\
\hline Fabricación de productos informáticos & 0 & 1 \\
\hline Fabricación de material y equipo eléctrico & 0 & 1 \\
\hline TOTAL & 118 & 1.965 \\
\hline
\end{tabular}

Fuente: Ministerio de Trabajo y Seguridad Social: Explotación estadística de datos de afiliación de trabajadores al sistema de la Seguridad Social por régimen, municipio y actividad (CNAE-09), diciembre de 2010.

quedando bajo el influjo de otros enclaves de mayor pujanza y dinamismo, $y$, muy especialmente, al socaire de las influencias metropolitanas de Madrid, de las que pueden derivar, a la postre, sus rentas de localización.

La ciudad de Ávila se ha construido pausadamente sobre los mimbres del pasado hasta conformar, en la actualidad, un compacto entramado urbano. Este ha conocido un crecimiento espacial sin precedentes a lo largo de los últimos sesenta años y, particularmente, durante la primera década de los años dos mil, fruto de una vinculación, que no siempre está correspondida, entre la evolución poblacional y el desarrollo residencial.

La positiva evolución demográfica experimentada por Ávila entre 2001 y 2011 (11.041 residentes) solamente puede ser explicada, en el marco de la dinámica expansiva asociada a todas las áreas urbanas de Castilla y León, por un aumento del vecindario en la ciudad compacta, no contando con los procesos de periurbanización consustanciales a la práctica totalidad de las ciudades medias de la Comunidad, como lo atestigua el hecho de que los bordes urbanos de la ciudad se descubren nítidamente por oposición a la dominancia que adquiere la ruralidad en el resto de un término municipal escasamente urbanizado.

Así, con ausencias de crecimientos exógenos de entidad, la ciudad de Ávila se ha desarrollado enormemente en un proceso de ampliación del espacio construido cuyo soporte estratégico se ha fundamentado, además, en la dialéctica establecida entre el centro y la periferia. De este modo, frente al descenso generalizado de la po- 
blación residente en la ciudad tradicional y los barrios aledaños a esta, dos han sido los grandes segmentos de creación ex nova que concentran los nuevos desarrollos urbanísticos desde el decenio de 1980; los ubicados y expandidos hacia levante a norte y sur del espacio nuclear.

1.964 edificios levantados en las dos décadas finales del siglo xx y otros 2.284 a lo largo del lapso 2001-2011 marcan los ritmos de un ensanchamiento del perímetro urbanizado desconocido, en lo que vienen siendo las trazas de la Ávila contemporánea: la finisecular y la del boom inmobiliario.

Una ciudad que se construye, aparte de por las notables pulsaciones poblacionales, en visos de ralentización y decaimiento presente, por la pérdida de significado de la inmigración extranjera y la atenuación de los saldos positivos de la dinámica natural, dimensionada desorbitadamente por la conjunción de una serie de intereses urbanísticos completamente truncados por el estallido de la crisis que asola el panorama nacional (46\% de la producción inmobiliaria de estos años se encuentra desocupada).

La Ávila de los «100.000», que propugnaba el Plan Estratégico de Desarrollo Industrial de 2006, idea recogida por el Avance del Plan General de Ordenación Urbana en tramitación, parece ser más una utopía que una realidad, a tenor de las proyecciones demográficas realizadas que atisban un horizonte demográfico para el entorno de 2030 de sostenimiento en el mejor de los casos. Es lo que algunos autores han catalogado como «anticipar el futuro al margen de la historia o diseñar una ciudad al margen de la ciudad conocida» (Calderón, 2013, p. 87).

Porque lo cierto es que la dinámica urbana abulense no pasa por su momento más halagüeño. Con unas tasas de paro superiores al $20 \%$ (las más altas de entre las capitales de provincia de Castilla y León), el mercado de trabajo local refleja la saturación de las actividades de servicios en lo que a capacidad de creación de empleo se refiere. Son los límites de la terciarización que ha fundamentado el devenir económico de la ciudad. Un problema estructural de muy difícil solución por cuanto Ávila se ha erigido, de siempre, como un centro de administración y prestación de servicios capitalinos, a la par que deudor de su tradicional vocación comercial.

Es el difícil mantenimiento de una herencia histórica en lo que al funcionamiento de la economía local y de la ligazón de la ciudad con su contorno se refiere. Son las llamadas de atención contenidas en los planes de revitalización o los informes de situación que esporádicamente han venido acompañando el discurso político en aras del tan ansiado desarrollo local: el de Ávila, mirando al siglo XXI: revalorización, empleo y desarrollo urbano sostenible, de 2004, el citado plan industrial de 2006 o el Plan para la Dinamización Empresarial y la Generación de Empleo, en curso. La mirada de todos ellos se ha tornado, pues, hacia el resto de actividades que pudieran fomentar la creación de los puestos de trabajo capaces de mantener el dinamismo que la ciudad necesita para su desarrollo. Si bien lo cierto es que, hasta el presente, solamente el turismo, en base a la explotación de la sobresaliente riqueza patrimonial de la ciudad (Plan de Excelencia Turística), ha cobrado verdadera carta de entidad como catalizador de empleo. En el resto, la atonía de la producción manufacturera, en la que continua perfilándose como la penúltima ciudad de la Comunidad en el ranking industrial, y el escaso aprovechamiento del potencial agropecuario y paisajístico que debiera descansar sobre los excelentes recursos naturales que atesora el espacio municipal circundante, verdadero complemento a la ciudad, y en muchas ocasiones postergado o cuando menos olvidado, condicionan esa reestructuración urbana y funcional de la que adolece Ávila a día de hoy.

\section{BIBLIOGRAFIA}

ANDRÉS LÓPEZ, G. (2008): «Geografía y ciudades medias en España: $i$ a la búsqueda de una definición innecesaria?». Scripta Nova, vol. XII, núm. 270 (49), 18 pp.

Calderón Calderón, B. (2001): «Un espacio creado y transformado por el permanente conflicto entre centro y periferia: una hipótesis - más - para interpretar el modelo de crecimiento urbano en España», en F. Manero Miguel (coord.): Espacio natural y dinámicas territoriales. Homenaje al Dr. D. Jesús García Fernández. Universidad de Valladolid, Valladolid, pp. 589-598.

- (2012): «Áreas urbanas y estructura de las ciudades de Castilla y León», en J. M. ${ }^{a}$ Delgado Urrecho (dir.): Población y poblamiento en Castilla y León. Consejo Económico y Social de Castilla y León, Valladolid, pp. 739-810.

- (2013): «De la ley al territorio: legislación, planeamiento y ciudad en los planes generales de Castilla y León, 1997-2010», en M. Valenzuela Rubio (coord.): Las ciudades españolas en la encrucijada: entre el boom inmobiliario y la crisis económica. Real Sociedad Geográfica, Madrid, pp. 77-110.

Delgado Viñas, C. (1993): Las pequeñas y medianas capitales de provincia en el proceso de modernización 
del sistema urbano español. Universidad de Las Palmas de Gran Canaria, Las Palmas de Gran Canaria, $228 \mathrm{pp}$.

EzQuiaga Domínguez, J. M. a (dir.) (2006): El territorio de Ávila: un paisaje en evolución. Junta de Castilla y León, Salamanca, $228 \mathrm{pp}$.

Fernández Sánchez, J. A., J. Villar Castro, D. J. Sánchez Zurro y E. Delgado Huertos (1989): Las ciudades, en A. Cabo y F. Manero (dirs.): Geografía de Castilla y León. T. 6, Ámbito, Valladolid, 182 pp.

Hortelano Mínguez, L. A. (2010): «Ávila: desarrollo urbano, conservación del patrimonio cultural y uso turístico sostenible», en Simposio Internacional Soluciones Sostenibles para las Ciudades Patrimonio Mundial. Fundación del Patrimonio Histórico de Castilla y León, Valladolid, pp. 141-161.

LóPEz Trigal, L. (1998): «Áreas urbanas y ciudades medias de Castilla y León. Rasgos, problemas y políticas». Medio Ambiente en Castilla y León, núm. 9, pp. 44-49.

Manero Miguel, F. (1995): «Readaptación de las jerarquías funcionales y transformación del espacio urbano en Castilla y León». Situación, núm. 3, pp. 217-233.

- (2003): «La transformación del espacio regional: las políticas territoriales», en F. Manero (coord.): La entidad recuperada (veinte años de Castilla y León, 1983-2003). Ámbito, Valladolid, pp. 191-245.

Martínez Fernández, L. C., y J. A. Luengo Gallego (2004): «Concentración y difusión de la actividad industrial en Castilla y León. El papel de las infraestructuras de transporte en las dinámicas territoriales». Revista de Economía y Finanzas de Castilla y León, núm. 9, pp. 51-76.

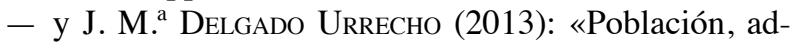
ministración y territorio en Castilla y León: desequilibrios y desafíos del modelo de poblamiento». Ería, núm. 90, pp. 5-30.

Pascual Ruiz-V aldepeñas, H. (2012): «El significado de la industria y de las nuevas infraestructuras en la estructuración territorial», en J. M. ${ }^{a}$ Delgado Urrecho (dir.): Población y poblamiento en Castilla y León. Consejo Económico y Social de Castilla y León, Valladolid, pp. 637-737.

Serrano Martínez, J. M. a (2004): «Expansión del parque inmobiliario en España. Algunas reflexiones desde la perspectiva territorial». Boletín Económico de ICE, núm. 2.798, pp. 11-30.

- (2010): «La edificación de viviendas en España, final del ciclo y ¿ocaso del modelo?». Boletín Económico de ICE, núm. 2981, pp. 37-55.
Solís Trapero, E. (2008): «El horizonte urbano madrileño: más allá de la región político-administrativa». Anales de Geografía, vol. 28, núm. 1, pp. 133-162.

Troitiño Vinuesa, M. A. (dir.) (1998): Ávila: turismo y realidad urbana. Fundación Cultural Santa Teresa, Ávila, 108 pp.

- y L. Troitiño Torralba (2009): «Turismo y patrimonio en Castilla y León: las ciudades patrimonio de la humanidad (Ávila, Salamanca y Segovia) como destinos turísticos de referencia». Polígonos. Revista de Geografía, núm. 19, pp. 145-178.

Villar CAStro, J. (1982): Geografía urbana de Ávila: raíces históricas en una ciudad actual. Tesis doctoral (inédita), Universidad de Salamanca, Salamanca, 1.164 pp. + anexos.

- (1984): «Organización espacial y paisaje arquitectónico en la ciudad medieval. Una aportación geográfica a la historia del urbanismo abulense». Cuadernos Abulenses, núm. 1, pp. 69-89.

- (1999): «Ávila: un centro administrativo lastrado de tradición», en A. J. Campesino (coord.): Comercio, turismo y cambios funcionales en las ciudades españolas patrimonio de la humanidad. Cámara de Comercio e Industria de Cáceres, Cáceres, pp. 61-80.

\section{FUENTES}

Ayuntamiento de Ávila (2010): Revisión del Plan General de Ordenación Urbana de Ávila. Documento de Avance. Información, Análisis y Diagnóstico. Conurma Ingenieros Consultores y Ayuntamiento de Ávila, Ávila, 417 pp.

- (2012): Ávila, empresa y empleo. Plan para la Dinamización Empresarial y la Generación de Empleo. Área de Empleo, Industria y Comercio del Ayuntamiento de Ávila, Ávila, 110 pp.

- (2013): Ávila. Estrategia de turismo 2015. Área de Turismo del Ayuntamiento de Ávila, Ávila, 86 pp.

- Explotación estadística del Padrón municipal (varios años).

- Observatorio de empleo (apuntes estadísticos del mercado laboral en 2013).

- Observatorio turístico de la ciudad de Ávila (varios años).

Cabero Diéguez, V. (dir.) (2004): Ávila, mirando al siglo XXI: revalorización, empleo y desarrollo urbano sostenible. Departamento de Geografía de la Universidad de Salamanca/Ayuntamiento de Ávila, Ávila, $237 \mathrm{pp}$. 
Caja España: Datos económicos y sociales de las unidades territoriales de España 2012.

Deloitte (2006): Plan Estratégico de Desarrollo Industrial de la Ciudad de Ávila. Ayuntamiento de Ávila/ Cámara Oficial de Comercio e Industria de Ávila, Ávila, 3 vols.

Instituto Geográfico Nacional (IgN) y Centro NacioNAL DE InFORMACIÓn GEOGRÁFICA (CNIG): CartoCiudad ( sistema de información de la red viaria, cartografía urbana y divisiones censal y postal de España).

- y Centro Nacional de Información Geográfica (CNIG): SIOSE (Sistema de Información sobre Ocupación del Suelo de España).

Instituto Nacional de Estadística (INE): Censo de población y viviendas (varios años).
- Estadística de variaciones residenciales (varios años).

- Movimiento natural de la población (varios años).

- Nomenclátor de entidades de población (varios años).

- Padrón municipal de habitantes (varios años).

LA CAIXA: Anuario económico de España 2012.

MinisTERIO DE FOMENTO: Transacciones inmobiliarias (compraventa).

Ministerio de Trabajo y Seguridad Social: Explotación estadística de datos de afiliación de trabajadores al sistema de la Seguridad Social por régimen, municipio y actividad (CNAE-O9), diciembre de 2010.

SIE (Almacén de datos multidimensional de la Junta de Castilla y León).

Universidad CATÓliCA DE Ávila: Observatorio socioeconómico de la provincia de Ávila (varios años). 